\title{
Participation of Tumor Necrosis Factor in the Mediation of Gram Negative Bacterial Lipopolysaccharide-induced Injury in Rabbits
}

John C. Mathison, Eleonora Wolfson, and Richard J. Ulevitch

Department of Immunology, Research Institute of Scripps Clinic, La Jolla, California 92037

\begin{abstract}
Macrophages are induced by LPS to release a number of products that determine the host response during gram negative sepsis. To examine the role of one such substance, tumor necrosis factor (TNF), in mediating LPS-induced injury, we employed a rabbit model of endotoxic shock to $(a)$ determine the kinetics and extent of release of TNF into plasma after injection of LPS, and (b) to evaluate the protective effect of in vivo neutralization of LPS-induced TNF by prior infusion of antiTNF antibody. TNF was maximally induced 45-100 min after injection of $10 \mu \mathrm{g}$ i.v. parent Salmonella minnesota Re595 LPS or $250 \mu \mathrm{g}$ Re595 LPS-HDL complexes. Maximal induction of TNF by LPS was associated with development of hypotension, focal hepatic necrosis, intravascular fibrin deposition and lethality. Based on (a) the peak levels of TNF observed in serum, $2.5 \times 10^{3} \mathrm{U} / \mathrm{ml}$, (b) the specific activity of purified rabbit macrophage-derived TNF, $1 \times 10^{8} \mathrm{U} / \mathrm{mg}$, and $(c)$ the biphasic disappearance of intravenously injected purified TNF $\left(t_{1 / 2}\right.$ $=0.5 \mathrm{~min}, 11 \mathrm{~min}$ ) we constructed a kinetic model showing that at least $130 \mu \mathrm{g}$ of TNF $\left(1.3 \times 10^{7} \mathrm{U}\right)$ was released into plasma 30-200 min postinjection of LPS. Prior infusion of anti-TNF antibody (30-45 min before LPS injection) resulted in neutralization of the LPS-induced serum TNF activity and provided significant protection from the development of hypotension, fibrin deposition, and lethality. Thus, these results provide further evidence that TNF plays a central role mediating the pathophysiologic changes that occur during gram negative endotoxic shock.
\end{abstract}

\section{Introduction}

Complications of gram negative sepsis include hypotension, fever, metabolic acidosis, disseminated intravascular coagulation (DIC), ${ }^{1}$ and death. The search for the toxic principal of

Address reprint requests to Dr. Mathison, Department of Immunology, IMM 12, Research Institute of Scripps Clinic, 10666 North Torrey Pines Road, La Jolla, CA 92037.

Received for publication 12 August 1987 and in revised form 7 December 1987.

1. Abbreviations used in this paper: CT, core temperature; HrTNF, human recombinant TNF; LPS-HDL, Re595 lipopolysaccharide-high density lipoprotein complexes; MAP, mean arterial pressure; $P$. acnes, Propionibacterium acnes; PA-LPS, plasma-altered LPS formed by exposure of parent Re595 LPS to serum; Parent LPS, lipopolysaccharide extracted from Salmonella minnesota Re595; PEM, peritoneal exudate macrophages obtained from mineral oil-treated rabbits; PEMTNF, tumor necrosis factor derived from rabbit PEM; TNF, tumor necrosis factor.

J. Clin. Invest.

(c) The American Society for Clinical Investigation, Inc. $0021-9738 / 88 / 06 / 1925 / 13 \$ 2.00$

Volume 81, June 1988, 1925-1937 gram negative bacteria led to the discovery that gram negative culture filtrates, extracted endotoxin (protein-LPS), purified LPS, and lipid A induce pathophysiologic changes characteristic of septic shock when injected into humans or experimental animals (1-4). Recent studies have focused on interactions of LPS with formed blood elements, plasma proteins and tissue-fixed cells in order to better understand the molecular mechanisms that lead to LPS-induced injury (1). For example, LPS has been shown to interact with a number of plasma constituents including complement proteins, coagulation factors, HDL and a newly recognized acute phase reactant (1, 5-7). Analysis of LPS interactions with cells demonstrated the importance of macrophages as primary targets for LPS when the in vivo tissue distribution of radiolabeled LPS was analyzed at the cellular level (8).

The central role of macrophages in mediating the host response to LPS has been suggested by a number of experiments such as the studies of Glode et al. showing that reconstitution of irradiated $\mathrm{C} 3 \mathrm{H} / \mathrm{HeJ}$ (LPS-nonresponsive) mice with spleen cells from $\mathrm{C} 3 \mathrm{H} / \mathrm{HeN}$ (LPS-responsive) mice rendered the $\mathrm{HeJ}$ mice responsive to LPS (9). More recently Galanos et al. have shown that transfer of bone marrow-derived macrophages from $\mathrm{C} 3 \mathrm{H} / \mathrm{HeN}$ mice to irradiated $\mathrm{C} 3 \mathrm{H} / \mathrm{HeJ}$ mice results in reconstitution of the LPS-responsiveness of the $\mathrm{C} 3 \mathrm{H} / \mathrm{HeJ}$ mice (10). It is now appreciated that macrophages are induced by LPS to release a number of products that participate in the mediation of injury (11), including the monokine termed tumor necrosis factor (TNF)/cachectin $(12,13)$.

The potential of TNF as a mediator of endotoxin-induced injury was first considered when Beutler et al. isolated the macrophage product termed cachectin, and amino acid sequencing and bioassays confirmed the identity of cachectin and TNF (14). These studies were extended to show that pretreatment of mice with anticachectin antiserum provided a modest protection from the lethal effects of endotoxin (15). Moreover, infusion of recombinant TNF/cachectin into rats, dogs, and mice induces a number of pathophysiologic changes not unlike those observed in septic shock (16-18).

Unfortunately, there have been no studies to date using well established animal models of endotoxic shock performed with highly purified preparations of LPS where TNF levels in the blood are quantitated, correlated with physiologic changes, and the effect of passive administration of anti-TNF antibodies on LPS-induced injury evaluated. This study attempts to bridge this gap. Herein we describe the isolation and characterization of rabbit macrophage-derived TNF, the dose dependency of LPS-induced TNF production in rabbits using two different forms of Salmonella minnesota Re595 LPS, namely parent LPS and LPS-HDL complexes and a kinetic modeling analysis that describes TNF production and release into the blood. In addition, experiments are described that provide evidence for an important role of TNF as a mediator of LPS-induced injury since pretreatment of rabbits with anti-TNF antibody significantly protects rabbits from LPS-induced injury and death. 


\section{Methods}

Animals. Outbred New Zealand White rabbits, male, 1.5-2.5 kg purchased from a commercial supplier were maintained on a standard pelleted diet for 7-14 d before use. Nubian strain goats $(70 \mathrm{~kg})$ were utilized for antibody production.

LPS. S. minnesota Re595 bacteria were obtained from A. Nowotny (University of Pennsylvania, Philadelphia) and grown in 5501 fermenters using a $0.1 \mathrm{M}$ phosphate-buffered medium containing $2.25 \%$ yeast extract, $1.1 \%$ peptone, and $1 \%$ cerelose (baker's glucose). The bacteria were harvested at late log phase growth, washed in distilled water, and lyophilized. LPS was extracted from the bacteria using the phenol-chloroform-petroleum ether (PCP) method of Galanos (19). After the final ether wash, the dried LPS was suspended in $20 \mathrm{mM}$ EDTA, pH 7.5, to a final concentration of $10 \mathrm{mg} / \mathrm{ml}$ and sonicated (four 20-30-s bursts at $50 \%$ output using a model W-375 sonicator; Heat Systems-Ultrasonics, Inc., Plainview, NY) until the solution was clarified. The LPS solution was dialyzed against sterile distilled water (six changes over $3 \mathrm{~d}$ ) and lyophilized. Stock solutions of the LPS (5 $\mathrm{mg} / \mathrm{ml}$ ) were prepared by sonication in $20 \mathrm{mM}$ EDTA, $\mathrm{pH}$ 7.5. LPS for use in tissue culture was dialyzed against sterile saline until free of EDTA, followed by determination of the final concentration of LPS using an assay for keto-deoxyoctulosonaté (20). Parent LPS for in vivo studies was prepared by diluting the stock LPS in sterile saline as required for a 1-ml injection. Plasma-altered LPS (PA-LPS) for injection was prepared by incubating parent LPS $(0.5 \mathrm{mg} / \mathrm{ml}$ final concentration) in $10 \mathrm{mM}$ EDTA anticoagulated isologous platelet free plasma for $30 \mathrm{~min}$ at $37^{\circ} \mathrm{C}$ followed by dilution with an equal volume of sterile saline. Partially purified LPS-HDL complexes were prepared by adding $2.1 \mathrm{~g}$ solid cesium chloride to $5 \mathrm{ml}$ freshly prepared PA-LPS followed by centrifugation for $60 \mathrm{~h}, 40,000 \mathrm{rpm}$ in a SW50.1 rotor (Beckman Instruments, Inc., Palo Alto, CA). The upper 20\% of the gradient was collected and dialyzed against six changes of sterile saline over $3 \mathrm{~d}$. Biosynthetically radiolabeled ${ }^{3} \mathrm{H}-\mathrm{Re} 595$ LPS (extracted as described above from bacteria grown in the presence of $\left[{ }^{3} \mathrm{H}\right]$ acetate) was used to quantitate recovery and determine the final concentration of LPS in the LPS-HDL preparation.

Cytolytic assay for TNF. TNF activity was measured using a cytolytic assay with actinomycin D-treated L929 cells as described by Ruff and Gifford (21). L929 cells (CCL 1; American Type Culture Collection, Rockville, MD) were maintained in RPMI 1640 supplemented with $10 \mathrm{mM}$ Hepes and $10 \%$ fetal bovine serum (HyClone; F. S. Rehatuin, Reheis Chemical Co., Phoenix, AZ). Confluent cultures (3-4 $\times 10^{7}$ cells $/ 75 \mathrm{~cm}^{2}$ flask) were rinsed briefly with $0.05 \%$ trypsin (TRL3; Worthington Biochemical Corp., Freehold, NJ) in physiologic salt solution containing $5 \mathrm{mM}$ EDTA and $10 \mathrm{mM}$ Hepes, pH 7.4 (22), resuspended in fresh medium containing actinomycin $\mathrm{D}(1 \mu \mathrm{g} / \mathrm{ml})$ and added to 96 -well plates $\left(5-7 \times 10^{4}\right.$ cells/well). After $2 \mathrm{~h}$ in culture, serially diluted samples were added to the wells and the plates were incubated overnight $\left(5 \% \mathrm{CO}_{2}, 37^{\circ} \mathrm{C}\right)$. After microscopic evaluation, the medium was decanted, and the wells were filled with a solution of $0.2 \%$ crystal violet, $10 \%$ formalin and $0.01 \mathrm{M}$ phosphate, $\mathrm{pH} 7-7.5$ for $5 \mathrm{~min}$, washed thoroughly with water and dried. The degree of lysis was quantitated spectrophotometrically $(550 \mathrm{~nm})$ using a plate reader (model EL310; Bio-Tek Instruments, Inc., Burlington, VT) interfaced with an IBM-PC computer. Assay results were expressed as units per milliliter, with one unit defined as the amount of TNF resulting in lysis of $50 \%$ of the cells.

Rouitinely, 8-12 plates were set up per assay. Each plate included two laboratory standards, conditioned medium from Re595 LPStreated RAW 264.7 cells $\left(6 \times 10^{3} \mathrm{U} / \mathrm{ml}\right)$ and conditioned medium from Re595 LPS-treated rabbit PEM $\left(1.3 \times 10^{3} \mathrm{U} / \mathrm{ml}\right)$. These standards, in turn, were calibrated against human recombinant TNF (Cetus Corporation, Emeryville, CA; $2 \times 10^{7} \mathrm{U} / \mathrm{mg}$ ) and assay results were normalized accordingly. Samples were assayed in quadruplicate, and a coefficient of variation (SD/mean) of $0.12 \pm 0.08$ (SD) was observed. Using this assay, we could detect as little as $10 \mathrm{pg} / \mathrm{ml}$ of rabbit macrophage-derived TNF (specific activity $1 \times 10^{8} \mathrm{U} / \mathrm{mg}$ ). However because serum concentrations $>10 \%$ caused nonspecific rounding and loss of adherence of the L929 cells, the lower limit of detection of rabbit TNF in serum was $20 \mathrm{U} / \mathrm{ml}$ (corresponding to $0.2 \mathrm{ng} \mathrm{TNF} / \mathrm{ml}$ ).

Rabbit peritoneal exudate macrophages (PEM). NZW rabbits $(2-2.5 \mathrm{~kg})$ were given an intraperitoneal injection of 35 mineral oil (Drakeol 6VR; Pennreco, Butler, PA) containing $10 \mu \mathrm{g}$ cell wall preparation from BCG (BCG Cell Walls, R-200; Ribi Immunochem Research, Inc., Hamilton, MT). $3 \mathrm{~d}$ later, a bolus injection of $120 \mathrm{mg}$ sodium pentobarbital i.v. (Western Medical Supply Inc., Arcadia, CA) was made, followed by aseptic lavage of the peritoneum with $500 \mathrm{ml}$ ice-cold RPMI 1640 supplemented with $2 \mathrm{mM}$ L-glutamine, $1 \mathrm{mM} \mathrm{Na}$ pyruvate, $50 \mathrm{U} / 50 \mu \mathrm{g}$ penicillin/streptomycin per $\mathrm{ml}, 10 \mathrm{mM}$ Hepes, $2 \%$ fetal bovine serum, and $5 \mathrm{U} / \mathrm{ml}$ heparin. The harvested cells were centrifuged $\left(1,000 \mathrm{~g}, 10 \mathrm{~min}, 4^{\circ} \mathrm{C}\right)$ and resuspended in the above medium without FBS (serum-free medium). After an additional spin and resuspension in serum-free medium, the cells were counted using a hemocytometer and plated in $150 \mathrm{~cm}^{2}$ flasks at a density of 8-10 $\times 10^{7}$ macrophages/flask. After $2 \mathrm{~h}$ at $37^{\circ} \mathrm{C}, 5 \% \mathrm{CO}_{2}$, nonadherent cells were removed from the flasks by vigorous washing and replenishment with $20 \mathrm{ml}$ serum-free medium. The mineral oil induced peritoneal exudate cells, when examined using Wright's stained cytocentrifuge preparations, contained $\sim 60 \%$ macrophages, $35 \%$ neutrophils, and $5 \%$ lymphocytes. After plating and washing, the adherent cells were $>90 \%$ macrophages. TNF-containing conditioned medium was generated by incubating the macrophage cultures overnight in the presence of $0.1 \mu \mathrm{g}$ Re595 LPS/ml, and the conditioned medium was centrifuged $2,000 \mathrm{~g}$, $30 \mathrm{~min}$, and stored at $-20^{\circ} \mathrm{C}$.

To determine the response of PEM to the LPS preparations used in these studies, PEM were plated in six-well clusters $(3.5 \mathrm{~cm}$ wells, 5 $\times 10^{6} \mathrm{PEM} /$ well, $1.25 \mathrm{ml}$ serum-free medium) and after washing and replenishment of medium, parent LPS, PA-LPS or LPS-HDL was added over the LPS dose-response range, $10 \mathrm{pg} / \mathrm{ml}$ to $1 \mu \mathrm{g} / \mathrm{ml}$. After 18 $h$ the conditioned medium was centrifuged and tested for TNF (cytolytic) activity. As shown in Fig. 1, TNF was maximally induced by $1-10 \mathrm{ng} / \mathrm{ml}$ parent LPS, whereas $0.1-1 \mu \mathrm{g} / \mathrm{ml}$ PA-LPS or LPS-HDL was required for maximal induction.

Purification of rabbit TNF from conditioned medium of LPStreated PEM. TNF containing PEM supernatants were pooled to yield 3 liters, and the following additions were made: (final concentration) 10 mM EDTA, $0.05 \%$ octyl $\beta$-D glucopyranoside (OG; Calbiochem, La Jolla, CA) and $0.5 \mathrm{M} \mathrm{NaCl}$, followed by application to a DEAE cellulose column $(2.25 \times 15 \mathrm{~cm}$, Amicon Matrix Cellufine AM; Amicon Corp., Danvers, MA). The flow-through material was concentrated 75-fold using a 10,000 mol wt cut-off filter (Millipore PTGC), and diafiltration was performed using $20 \mathrm{mM}$ Tris-buffered $0.05 \%$ OG, $\mathrm{pH}$ 7.5 until the conductivity was below $2 \mathrm{mMho}$. OG was added $(0.5 \%$ final concentration) to maximize recovery of TNF, and the material was applied to a Fractogel TSK DEAE-650s (EM Science, Gibbstown, NJ) column $(2.5 \times 6 \mathrm{~cm})$ using a 50 -ml superloop (Pharmacia Fine Chemicals, Piscataway, NJ) with a series 4 HPLC (Perkin-Elmer Corp., Norwalk, CT) (Fig. 2). After the flow-through peak was collected, the bound proteins were eluted with a linear gradient $(0-0.25 \mathrm{M} \mathrm{NaCl})$. The fractions $(7.5 \mathrm{ml} /$ fraction) containing cytolytic activity were

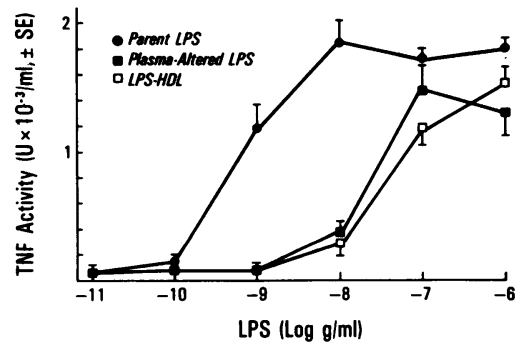

Figure 1. Induction of TNF in rabbit PEM by S. minnesota Re595 LPS. Adherent rabbit PEM were incubated overnight with parent LPS, PA-LPS or partially purified LPSHDL as described in Methods, followed by measurement of TNF activity in the conditioned medium using the $\mathrm{L} 929$ cytolytic assay. 




Figure 2. Purification of rabbit TNF. Conditioned medium from LPS-treated rabbit PEM was fractionated by HPLC anion exchange chromatography $(A)$, chromatofocusing $(B)$ and molecular exclusion chromatography $(C)$ as described in Methods. Results are shown in Table I.

pooled, concentrated to $5 \mathrm{ml}$, diluted 10 -fold with $25 \mathrm{mM}$ bis-Tris buffered $0.05 \%$ OG and applied to a Mono $\mathrm{P}$ chromatofocusing column which was eluted with pH 4 polybuffer (Polybuffer 74; Pharmacia, Uppsala, Sweden). The fractions ( $2 \mathrm{ml} /$ fraction) containing peak cytolytic activity were concentrated to $0.5 \mathrm{ml}$ and applied to a Pharmacia Superose-12 gel filtration column and $0.71 \mathrm{ml}$ fractions were collected. Results from a representative purification are shown in Figs. 2 and 3 and Table I. The specific activity of purified PEM-TNF was found to be $1 \times 10^{8} \mathrm{U} / \mathrm{mg}\left(1.8 \times 10^{15} \mathrm{U} / \mathrm{mol}\right)$ when tested on actinomycin D-treated L929 cells using a human recombinant TNF standard. Aliquots of the column fractions were heated $\left(100^{\circ} \mathrm{C}, 2 \mathrm{~min}\right)$ in sample buffer containing $10 \mathrm{mg}$ DTT/ml and electrophoresed on $15 \%$ polyacrylamide gels using the method of Laemmli followed by silver staining $(23,24)$. Molecular weight standards included: a) ovalbumin (43 kD), $\alpha$-chymotrypsin (26 kD), $\beta$-lactoglobulin (18 kD), lysozyme $(14 \mathrm{kD})$, and bovine trypsin inhibitor (6.2 kD) (Bethesda Research Laboratories, Gaithersburg, MD), and crosslinked cytochrome $c, 74$,

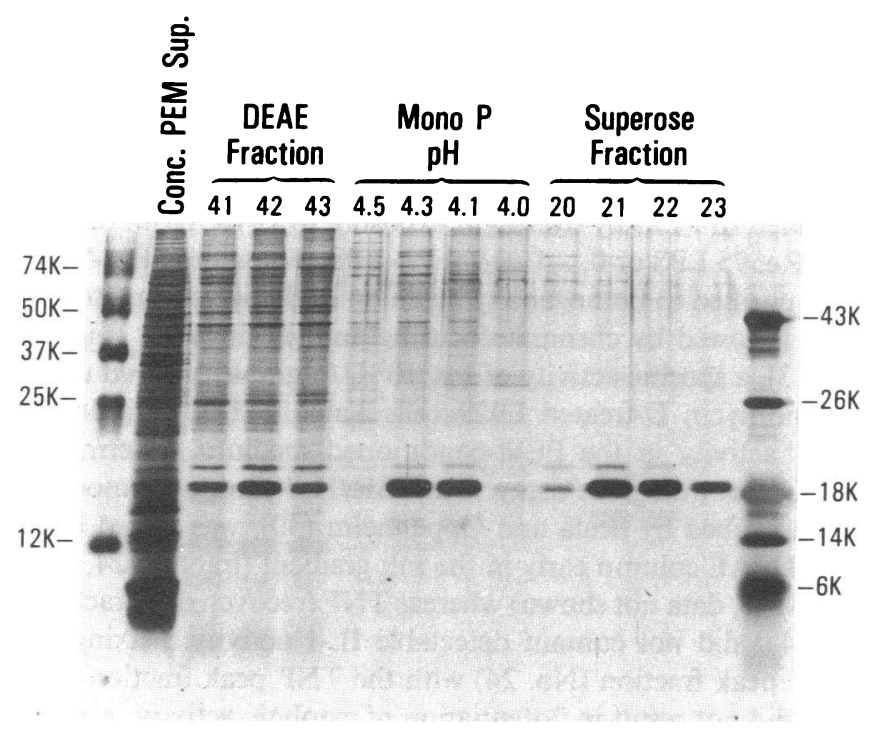

Figure 3. SDS-PAGE of TNF-containing fractions from the purification shown in Fig. 2. Samples were reduced using $10 \mathrm{mg}$ DTT/ml sample buffer, electrophoresed on $15 \%$ resolving gels, and silver stained as described in Methods.
$50,37,25$, and $12 \mathrm{kD}$ (United States Biochemical Corp., Cleveland, $\mathrm{OH})$. $\mathrm{NH}_{2}$-terminal sequence analysis of the purified PEM-TNF, which had been gel filtered using $50 \mathrm{mM}$ ammonium bicarbonate buffer, was performed by K.W.K. Watt of Cetus Corporation using an Applied Biosystems gas phase sequenator followed by analysis of phenylthiohydantoin derivatives of the AA residues by HPLC with the following results:

VASRALSDK P LA H V V A N P V

2130

E (G) Q L (Q) (?) L I P R P

Alternative identities for residues $1,3,29$, and 31 were $S, L, N$, and A, respectively. These results are in agreement with previously published sequence data for rabbit TNF $(25,26)$.

Purified PEM-TNF was radioiodinated using the iodogen method (27). Briefly, a $10 \times 75 \mathrm{~mm}$ glass tube was coated with $2 \mu \mathrm{g}$ iodogen (Pierce Biochemicals, Rockford, IL) dissolved in $100 \mu$ l methylene chloride, followed by drying under a stream of nitrogen gas. After rinsing the tube with $0.1 \mathrm{~m}$ PBS pH 7.4, $20 \mu \mathrm{g}$ PEM-TNF was added in a volume of $20 \mu \mathrm{l}$ phosphate saline followed by the addition of $1 \mathrm{mCi}$ ${ }^{125} \mathrm{I}-\mathrm{Na}$ (IMS.300; Amersham, Arlington Heights, IL). After $20 \mathrm{~min}$ of gentle agitation at room temperature, the reaction mixture was dialyzed against $0.1 \mathrm{M}$ phosphate saline until free of unbound iodine. The ${ }^{125} \mathrm{I}-\mathrm{TNF}$ had a specific activity of $1 \mu \mathrm{Ci} / \mu \mathrm{g}$, was $>90 \%$ precipitable in $10 \%$ TCA and remained fully active in the L929 assay.

Antibody production. Polyclonal anti-TNF antibody was produced by immunizing goats with human recombinant TNF (carrier-free, 2 $\times 10^{7} \mathrm{U} / \mathrm{ml},<20 \mathrm{ng}$ endotoxin/mg TNF) which was provided by Cetus Corp. The initial immunization was made with $50 \mu \mathrm{g}$ TNF emulsified using the Ribi adjuvant system containing $50 \mu \mathrm{g}$ monophosphoryl lipid A, $100 \mu \mathrm{g}$ trehalose dimycolate, and $20 \mu$ l squalene in a final volume of $2 \mathrm{ml} 0.2 \%$ Tween 80 in sterile saline (Ribi Immunochemical Research, Hamilton, MT). Booster injections given on weeks 3,9 , and 12 consisted of $50 \mu \mathrm{g}$ antigen in saline. TNF emulsified in Freund's complete adjuvant was administered on week 6. Terminal bleeding was performed 7-10 d after the final immunization. Blood collection and subsequent processing of serum was performed using pyrogen-free glassware or plastic ware and reagents. Because goat serum, normal as well as immune, was found to contain antibodies that agglutinated rabbit red blood cells, the following adsorption was performed. Rabbit blood was collected in acid citrate dextrose (28), and after centrifugation $(10 \mathrm{~min}, 700 \mathrm{~g}$ ) and aspiration of the plateletrich plasma, the red cells were washed three times by centrifugation ( 5 min, $2,000 \mathrm{~g}$ ) and resuspension in $10 \mathrm{mM}$ Hepes saline, $\mathrm{pH} \mathrm{7.1}$ vol of packed cells was suspended in $9 \mathrm{vol}$ of goat serum, and after $10 \mathrm{~min}$ with gentle mixing at $0^{\circ} \mathrm{C}$, the cells were pelleted $(5 \mathrm{~min}, 2,000 \mathrm{~g})$ and the serum was harvested. Globulin fraction was prepared by mixing equal volumes of the adsorbed serum with saturated ammonium sulphate (Ultrapure grade; Schwartz/Mann Biotech, Cleveland, $\mathrm{OH}$ ), $\mathrm{pH}$ 7 , for $2 \mathrm{~h}, 0^{\circ} \mathrm{C}$ followed by centrifugation $(2,000 \mathrm{~g}, 30 \mathrm{~min})$ and solubilization of the precipitate in $10 \mathrm{mM}$ Hepes saline, pH 7. After two additional precipitations, the globulin fraction was dialyzed against $10 \mathrm{mM}$ Hepes saline, $\mathrm{pH} \mathrm{7,} \mathrm{for} 24 \mathrm{~h}$, exposed to $1 \mathrm{mM}$ diisopropylfluorophosphate (DFP) for $30 \mathrm{~min}$ at room temperature and further dialyzed against five changes of Hepes saline over $60 \mathrm{~h}$. The final protein concentration was $42 \mathrm{mg} / \mathrm{ml}$ for the anti-TNF globulin and $31 \mathrm{mg} / \mathrm{ml}$ for the NGG.

The neutralizing capacity of the antibody was determined by mixing equal volumes of HrTNF or PEM-TNF $\left(1-2 \times 10^{3} \mathrm{U} / \mathrm{ml}\right)$ with various dilutions of the antiserum or globulin fraction. After $60 \mathrm{~min}$ at $37^{\circ} \mathrm{C}$, the mixtures were tested for residual cytolytic activity in the L929 assay. As shown in Fig. 4, anti-HrTNF globulin fraction provided $50 \%$ neutralization of $\mathrm{HrTNF}$ when diluted 1,000 -fold, whereas $50 \%$ neutralization of PEM-TNF was observed with 80- to 100-fold diluted antibody. When anti-HrTNF globulin fraction was applied to a Superose-12 gel filtration column, all of the TNF neutralizing activity was 
Table I. Purification of Tumor Necrosis Factor from Conditioned Medium from LPS-treated Rabbit Peritoneal Exudate Macrophages

\begin{tabular}{lcccrrr}
\hline \multicolumn{1}{c}{ Step } & Volume & Protein & Cytolytic activity & Specific activity & Purification \\
& $m l$ & $m g$ & $U$ & $U / m g$ & fold \\
Conditioned medium & 3,000 & 58 & 1.1 & $8 \times 10^{6}$ & $1.4 \times 10^{5}$ & 1 \\
DEAE & 7.5 & 0.12 & $7.5 \times 10^{6}$ & $6.8 \times 10^{6}$ & 49 \\
Mono P & 4 & 0.028 & $3.2 \times 10^{6}$ & $1.1 \times 10^{8}$ & 286 \\
Superose-12 & 1.4 & & & 786
\end{tabular}

recovered with an apparent $150,000 \mathrm{~mol}$ wt. In preliminary in vivo experiments we found that the cytolytic activity $\left(2-3 \times 10^{3} \mathrm{U} / \mathrm{ml}\right)$ of serum which was collected 50-100 min after injection of $10 \mu \mathrm{g}$ Re595 LPS was neutralized $>95 \%$ after incubation $\left(60 \mathrm{~min}\right.$ at $\left.37^{\circ} \mathrm{C}\right)$ with 10-fold diluted goat anti-HrTNF globulin. Moreover, infusion of 2-4 $\mathrm{ml}$ i.v. of the globulin fraction of anti-TNF was sufficient to neutralize (>95\%) the serum cytolytic activity which appeared 45-100 min after injection of $10 \mu \mathrm{g}$ i.v. parent LPS (data not shown).

To rule out the possibility that the goat anti-TNF antiserum contained antibodies specific for Re595 LPS, we tested preimmune, immune, and control goat serum and globulin fractions using an enzyme-linked immunoassay that could detect as little as $1 \mathrm{ng}$ antiRe595 and were unable to detect specific antibody in any of the samples, indicating that immunization of the goats with HrTNF did not induce an anti-LPS response.

Importantly, when tested in a chromogenic Limulus Assay (Whittaker M.A. Bioproducts, Walkersville, MD) endotoxin contamination was observed to be $<0.5 \mathrm{ng} / \mathrm{ml}$. Moreover, injection of $8 \mathrm{ml}$ i.v. of the globulin fraction did not induce significant elevation of core temperature in rabbits $\left(<0.4^{\circ} \mathrm{C}\right.$ increase), although transient leukopenia (40-60\% decrease in WBC levels) was observed (5-15 min) postinjection with recovery to normal WBC levels by $30 \mathrm{~min}$.

In vivo studies. Rabbits were fasted overnight to achieve normalization of the nutritional status. At 7 a.m. the following morning, the rabbits were briefly secured in the supine position, and a femoral artery cannula was placed to the level of the lower abdominal aorta using local anesthesia $(2 \mathrm{ml} 1 \%$ procaine; Breon Laboratories, Inc., New York). The surgical wound was sutured, and the rabbits were placed in restraining suits (Torso Sling Suits; Alice King Chattam, Los Angeles, CA) that permitted the animals to stand or recline in the prone position without disrupting experimental procedures (injections, blood collection, and monitoring of mean arterial pressure and core temperature). After baseline parameters were established, saline, NGG, or anti-TNF globulin was infused (routinely $8 \mathrm{ml}$ injected through the marginal ear vein over $4 \mathrm{~min}$ ) 30-45 $\mathrm{min}$ before injection of LPS at $t=0$ (usually

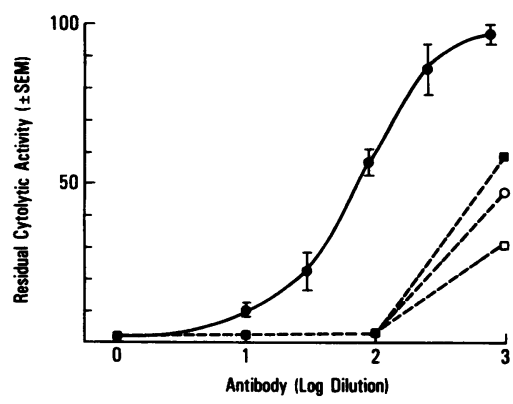

Figure 4. In vitro neutralization of TNF activity. Rabbit PEMTNF (conditioned medium from LPS-treated macrophages) or human recombinant TNF $\left(1-2 \times 10^{3} \mathrm{U} / \mathrm{ml}\right)$ was mixed with equal volumes of diluted antibody, (goat anti-HrTNF globulin, rabbit anti-

HrTNF antiserum or rat anti-PEM-TNF antiserum) followed by incubation at $37^{\circ} \mathrm{C}$ for $60 \mathrm{~min}$. Residual cytolytic activity was determined using the L929 cell assay as described in Methods. The following reactions are shown: goat anti-HrTNF vs. PEM-TNF, ^; goat anti-HrTNF vs. HrTNF, o; rabbit anti-HrTNF vs. HrTNF, 口; rat anti-PEM-TNF vs. PEM-TNF, $m$.
9:30-10:00 a.m.). In some of the experiments controlled infusions were made through the femoral vein catheter using a Holter Roller pump with a size D chamber (Series 900 , Critikon, Inc., Tampa, FL). Monitoring of MAP and CT and collection of blood samples proceeded for 200-500 min. Representative physiologic parameters in cannulated rabbits at the beginning of the observation period were: MAP, $98 \pm 2 \mathrm{mmHg}$; CT, $38.8 \pm 0.17^{\circ} \mathrm{C}$; WBC, $6200 \pm 500 \mathrm{cells} / \mathrm{mm}^{3}$ (mean \pm SE, $n=6$ ). Parameters observed 500 min postinjection of $1 \mathrm{ml}$ sterile saline were: MAP $94 \pm 3 \mathrm{mmHg}$; CT, $39 \pm 0.14^{\circ} \mathrm{C}$; WBC, $8600 \pm 800$ cells $/ \mathrm{mm}^{3}$. Upon completion of the observation period, animals were sacrificed by injection of $120 \mathrm{mg}$ i.v. sodium pentobarbital, or when further monitoring was required, the cannula was disinfected and closed, and the rabbits were returned to cages. On the following morning, collection of blood samples and monitoring of parameters was continued, and in some cases repeat injections of LPS were made. In the course of the experiments, animals recognized as being moribund (in general, MAP $<55 \mathrm{~mm}$ and $\mathrm{CT}<36^{\circ} \mathrm{C}$ ) were sacrificed by intravenous injection of sodium pentobarbital. Autopsies were performed, and tissues were prepared for histologic examination.

Protein measurement. Protein concentrations in serum globulin fractions and column fractions from the TNF purification were determined using BCA reagent (Pierce Biochemicals, Rockford, IL).

Statistical methods. Data are expressed as mean \pm SE. Differences in MAP between saline or NGG pretreated and anti-TNF pretreated animals were analyzed for statistical significance using a distributionfree (nonparametric) test developed by Koziol et al. (29).

\section{Results}

As a basis for these studies we first determined conditions for optimal production of TNF in vitro by rabbit PEMs. In addition, a procedure was devised to purify rabbit TNF so that the specific activity and in vivo circulating half-life of the TNF could be determined. As shown in Fig. 1, TNF is maximally induced in PEM by overnight exposure to $1-10 \mathrm{ng} / \mathrm{ml}$ of parent Re595 LPS or 0.1-1 $\mu \mathrm{g} / \mathrm{ml}$ PA-LPS. When the PEM-TNF was purified to homogeneity by anion exchange chromatography followed by chromatofocusing and gel filtration (Figs. 2 and 3), a specific activity of $1 \times 10^{8} \mathrm{U} / \mathrm{mg}$ was observed using actinomycin D-treated L929 cells Table I. The majority of IL-1 activity in the PEM-conditioned medium, determined using a comitogenic assay with $\mathrm{C} 3 \mathrm{H} / \mathrm{HeJ}$ mouse thymocytes as described by Scala and Oppenheim (30), was eluted from the DEAE column early in the salt gradient (fraction 24, 0.05 $\mathrm{M} \mathrm{NaCl}$, data not shown) whereas TNF (recovered in fractions 41-43) did not contain detectable IL-1 activity. Mixing the IL-1 peak fraction (No. 24) with the TNF peak fraction (No. 42) did not result in potentiation of cytolytic activity. A small amount of cytolytic activity was observed in fraction 24 (500 $\mathrm{U} / \mathrm{ml}$ ), albeit a minimal amount compared to the cytolytic activity in the TNF peak (No. $42,1 \times 10^{6} \mathrm{U} / \mathrm{ml}$ ). The cytolytic activity of fraction 24 was not neutralized by anti-HrTNF an- 




as described in Methods. PA-LPS was administered as a bolus injection using the marginal ear vein, and blood samples were collected at the indicated times.

tibody, a finding consistent with published reports that IL-1 has cytolytic activity (31). These data indicate that the specific activity of rabbit TNF is 5-10-fold greater than that observed for purified human recombinant TNF. Comparable specific activities were suggested for purified HL60-derived TNF (32).

Induction of TNF in vivo by plasma-altered LPS in rabbits. We and others have shown previously that exposure of LPS to serum or plasma results in formation of LPS-HDL complexes (5, 33-35). Moreover, evidence has been presented suggesting that during gram negative sepsis LPS-HDL complexes may form as a consequence of interactions between bacteria and plasma (36). Because LPS-HDL complexes may play a role in inducing many of the pathologic changes of gram negative sepsis, we performed the following experiments to determine the efficacy of LPS-HDL in inducing TNF in vivo.

Rabbits were cannulated and placed in restraining suits for monitoring of physiologic parameters as described in Methods. After establishment of baseline parameters, an intravenous bolus of PA-LPS (PA-LPS, 250, 50, or $10 \mu \mathrm{g}$ of LPS injected) was administered using the marginal ear vein. As shown in Fig. 5, after injection of $250 \mu \mathrm{g}$ PA-LPS, peak levels of cytolytic activity $\left(2-3 \times 10^{3} \mathrm{U} / \mathrm{ml}\right)$ were observed over 45-100 min. Injection of $50 \mu \mathrm{g}$ PA-LPS resulted in substantially lower peak levels of TNF $(500 \mathrm{U} / \mathrm{ml})$, and after injection of $10 \mu \mathrm{g}$ PA-LPS a minimal response $(<250 \mathrm{U} / \mathrm{ml})$ was observed. Cytolytic activity levels decreased over 100-200 min and became undetectable $200 \mathrm{~min}$ after injection of LPS. As shown in Fig. 6, injection of $250 \mu \mathrm{g}$ PA-LPS resulted in a decrease in MAP occurring over 30-60 min followed by a further $25 \%$ decrease over $125-500 \mathrm{~min}$. After injection of 50 or $10 \mu \mathrm{g}$ PA-LPS, MAP remained in the normal range for 200 min followed by a $30 \%$ decrease over $200-500 \mathrm{~min}$. Each of the doses of PA-LPS employed resulted in leukopenia (15-100 $\mathrm{min}$ ) followed by a gradual return to preinjection levels. In separate experiments, we observed that injection of $250 \mu \mathrm{g}$ LPS-HDL complexes purified by isopycnic density gradient centrifugation in $\mathrm{CsCl}$ resulted in induction of comparable levels of TNF and hypotensive change, and moreover, larger doses of PA-LPS (up to $500 \mu \mathrm{g}$ ) did not induce greater levels of TNF or result in more pronounced hypotension (data not shown).

Induction of TNF by parent LPS. We have shown previously that intravenously injected parent Re595 LPS is rapidly cleared from the blood and taken up by macrophages (8). Re595 LPS is highly aggregated (>10 $10^{6} \mathrm{~mol} \mathrm{wt}$ ) and maintenance of the aggregate is favored by the presence of divalent cations (e.g., $\mathrm{Ca}^{2+}$ and $\mathrm{Mg}^{2+}$ ). Thus disaggregation of parent

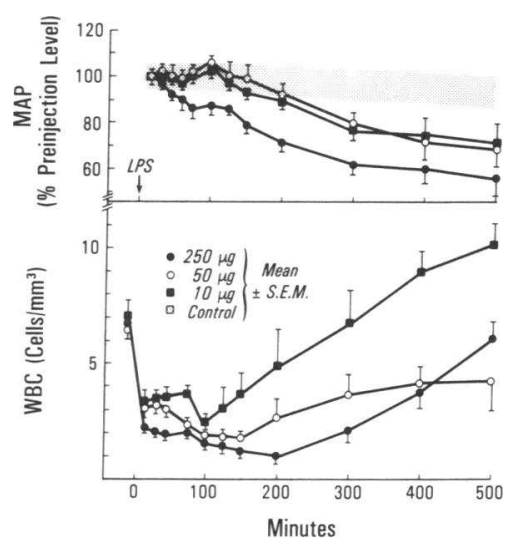

Re595 LPS (requisite for formation of LPS-HDL complexes) proceeds inefficiently in plasma or serum in the absence of chelating agents $(2,33)$. In contrast LPS-HDL complexes (preformed by exposure of parent LPS to $10 \mathrm{mM}$ EDTAserum) persist in the circulation with a half-life of $>12 \mathrm{~h} \mathrm{(8).}$ To determine if parent LPS would serve as a more efficient stimulus for TNF, a single, rapid injection of $250,50,10$, or 2 $\mu \mathrm{g}$ i.v. Re595 LPS in saline was administered, and blood samples were collected for measurement of serum TNF levels. As shown in Fig. 7, TNF was maximally induced by as little as 10 $\mu \mathrm{g}$ parent LPS. Peak levels of $<500 \mathrm{U} \mathrm{TNF} / \mathrm{ml}$ were observed after injection of $2 \mu \mathrm{g}$ LPS.

Because maximal induction of TNF by $250 \mu \mathrm{g}$ PA-LPS was associated with substantial hypotensive changes, we wondered if comparable blood pressure changes would result after injection of $10 \mu \mathrm{g}$ parent LPS. Furthermore, we asked whether administration of a second dose of LPS might induce further release of TNF and lead to acceleration of pathophysiologic changes. As shown in Fig. 8, a 10- $\mu \mathrm{g}$ bolus injection of parent LPS induced peak levels of $2-3 \times 10^{3} \mathrm{UTNF} / \mathrm{ml}$ as well as a $15-25 \%$ decrease in MAP over 15-100 min. Injection of a second dose of $10 \mu \mathrm{g}$ LPS at $300 \mathrm{~min}$ did not induce a detectable TNF release and the associated MAP decrease was $<10 \%$. These results suggested that when macrophages are maximally induced by LPS to release TNF into the blood, the cells are rendered unresponsive to further stimulation by LPS.

However we also considered the possibilities that LPS might induce inhibitors that would: $(a)$ block directly the cy-

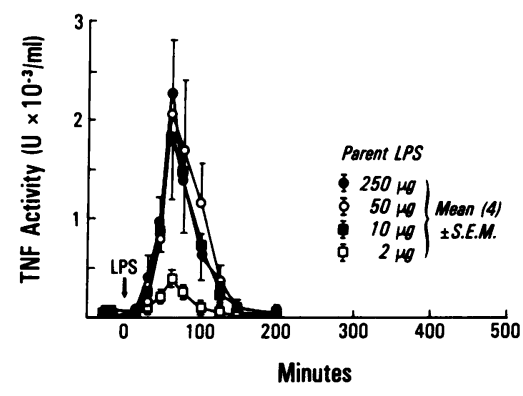

Figure 7. Induction of serum TNF by intravenous injection of parent Re595 LPS in rabbits. Femoral artery cannulation and injections were performed as described in Fig. 5 and Methods.

2. Leukocyte counts are expressed as cells $\times 10^{-3} / \mathrm{mm}^{3}$. 


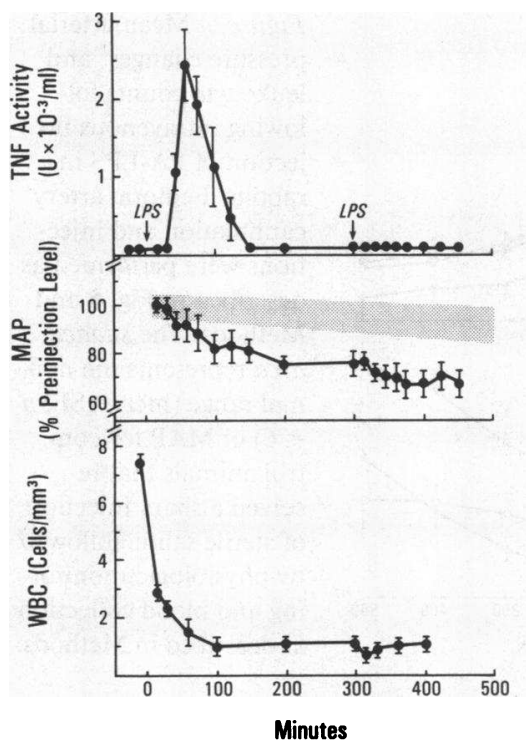

Figure 8. Induction of TNF and pathophysiologic changes ${ }^{2}$ in rabbits by intravenous injection of $10 \mu \mathrm{g}$ parent Re595 LPS at $t=0 \mathrm{~min}$ and $t=300 \min (n=4$, \pm SE). Femoral artery cannulation and injections were performed as described in Fig. 5 and Methods. The shaded area indicates $\mathrm{MAP} \pm \mathrm{SE}$ for control rabbits as indicated in Fig. 6.

tolytic activity of TNF or $(b)$ block further LPS-induction of TNF release. To test for the presence of inhibitor of cytolytic activity, serum samples from the above experiment (Fig. 8) were mixed with equal volumes of conditioned medium from LPS-treated rabbit PEM, and after a 30-min incubation at $37^{\circ} \mathrm{C}$, the mixtures were tested for cytolytic activity. As shown in Table II, good recoveries of PEM supernatant cytolytic activity was observed in all of the mixtures, suggesting that inhibitors of TNF cytolytic activity were not present in plasma either before or after LPS injection. Next, aliquots of the same serum samples were added to cultures of rabbit $\operatorname{PEM}(1,5$, and $10 \%$ final serum concentration) followed by addition of LPS ( 1 $\mu \mathrm{g} / \mathrm{ml}$ ), and after $18 \mathrm{~h}$ the conditioned medium was tested for TNF activity. As shown in Table III, LPS induction in vitro was not inhibited by serum that was collected either before or after injection of LPS in vivo. Thus, we did not find evidence for a serum inhibitor that would result in unresponsiveness of macrophages (or other TNF-producing cells) to a second dose of LPS in vivo.

Finally, to determine if TNF itself could render macrophages hyporesponsive to stimulation by LPS we exposed adherent rabbit PEM to human recombinant TNF over the dose response range 0.01 to $100 \mathrm{ng} / \mathrm{ml}$ for $2 \mathrm{~h}$ followed by addition of $10 \mathrm{ng} \mathrm{Re} 595 \mathrm{LPS} / \mathrm{ml}$. After $18 \mathrm{~h}$ at $37^{\circ} \mathrm{C}$ the conditioned medium was tested in the L929 cell assay, and no evidence for a direct effect of TNF on LPS-induced TNF production was

Table II. Recovery of Cytolytic Activity from Mixtures of PEM$T N F^{*}$ and Serum (Pre- and Post-TNF) from Rabbits that Received $10 \mu \mathrm{g}$ Parent Re595 LPS at $t=0$ and $300 \mathrm{~min}$

\begin{tabular}{lcccc}
\hline & \multicolumn{4}{c}{ Minutes post injection of LPS } \\
\cline { 2 - 5 } & -15 & 15 & 200 & 300 \\
\hline $\mathrm{U} / \mathrm{ml}$ & $660 \pm 40$ & $720 \pm 50$ & $910 \pm 70$ & $680 \pm 30$ \\
$\%$ Recovery & 102 & 111 & 140 & 105 \\
\hline
\end{tabular}

* Equal volumes of serum and conditioned medium from LPStreated rabbit PEM ( $1 \mu \mathrm{g}$ Re595 LPS, $\left.18 \mathrm{~h}, 1.3 \times 10^{3} \mathrm{U} \mathrm{TNF} / \mathrm{ml}\right)$ were mixed, incubated $30 \mathrm{~min}$ at $37^{\circ} \mathrm{C}, 5 \% \mathrm{CO}_{2}$, and tested in the L929 cytolytic assay. observed (data not shown). In further experiments we examined the effect of infusion of HrTNF on LPS induced TNF production in vivo (see below).

Determination of in vivo half-life of TNF and estimation of total amount of TNF released into plasma in vivo. To estimate the amount of TNF released into blood after injection of LPS in rabbits the following information was required: $(a)$ quantitation of plasma TNF levels in serum of LPS-treated animals, e.g., as shown in Fig. 5, and (b) knowledge of the circulating half-life of TNF in plasma. To determine the half-life of PEMTNF in vivo rabbits were cannulated and placed in restraining suits as described in Methods, and a bolus injection of one of the following was made using the marginal ear vein: $(a)$ condi-

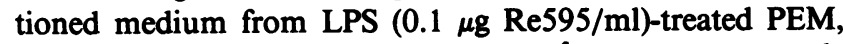
20-fold concentrated, containing $2 \times 10^{5} \mathrm{U}$ TNF in $4 \mathrm{ml}$; (b) fractogel-DEAE purified PEM-TNF, containing $5 \times 10^{5} \mathrm{U}$ TNF in $1 \mathrm{ml}$; or (c) PEM-TNF that was purified to homogeneity and labeled with ${ }^{125} \mathrm{I}$ as described in Methods $(0.5 \mathrm{ml}$ injection volume for a total of $\left.1 \times 10^{6} \mathrm{cpm}\right)$. Blood samples $(1 \mathrm{ml})$ were collected from the femoral artery catheter $0.5,1,2,3,5$, and 10 min postinjection, and serum cytolytic activity or ${ }^{125} \mathrm{I}$ TNF in blood was determined. As shown in Fig. 9, the disappearance of TNF from blood was biphasic and could be resolved into a fast component $\left(t_{1 / 2}\right.$ fast $\left.=0.5-1 \mathrm{~min}\right)$ and a slow component $\left(t_{1 / 2}=9-13 \mathrm{~min}\right)$. The TNF concentrations observed $0.5 \mathrm{~min}$ postinjection for the three different TNF preparations were $65 \%$ (conditioned medium), $80 \%$ (DEAE-purified), and $85 \%$ ( $\left.{ }^{125} \mathrm{I}-\mathrm{TNF}\right)$ of the maximal levels predicted on the basis of the blood or plasma volumes $(120$ or $70 \mathrm{ml}$, respectively as determined in previous studies) and the dose of TNF injected (8). In view of the sizeable quantity of TNF released into blood after injection of LPS, we considered the possibility that the clearance rate of TNF in LPS-treated rabbits might decrease, resulting in a longer circulating half-life. However, as shown in Fig. 9, when rabbits were pretreated with $10 \mu \mathrm{g}$ parent $\operatorname{Re} 595$ LPS at $t=0$ followed by injection of DEAE-purified PEM-TNF at $t=200 \mathrm{~min}$, the disappearance kinetics

Table III. TNF Cytolytic Activity in Conditioned Medium from PEM that were Exposed to LPS in the Presence of Serum (Pre- and Post-LPS) from Rabbits that Received $10 \mu \mathrm{g}$ Parent $L P S$ at $t=0$ and 300 min $^{*}$

\begin{tabular}{ccccccc}
\hline & \multicolumn{6}{c}{ Minutes post injection of LPS } \\
\cline { 2 - 7 } Serum \\
\cline { 2 - 7 } & -15 & 60 & 100 & 200 & 360 & 450 \\
\hline & \multicolumn{6}{c}{$U \times 10^{-3} / m l$} \\
$10 \%$ & $6.8^{11}$ & 4.3 & 3.7 & 4.5 & 4.5 & 6.1 \\
$5 \%$ & 5.4 & 3.1 & 2.9 & 3.7 & 2.7 & 3.1 \\
$1 \%$ & 6.8 & 5.7 & 6.9 & 5.5 & 5.5 & 6.1 \\
\end{tabular}

* Serum samples were from the multiple LPS injection experiment shown in Fig. 8.

₹ PEM were cultured in 6-well clusters in serum-free medium as described in Methods, and pooled serum samples $(n=4)$ from each time point were added to achieve a final concentration of 10,5 , or $1 \%$, followed by addition of parent Re595 LPS $(1 \mu \mathrm{g} / \mathrm{ml}$ final concentration).

${ }^{8}$ TNF activity was below background $(<30 \mathrm{U} / \mathrm{ml})$ in wells that received serum ( $10 \%$ final concentration) without LPS.

"All of the values are within 2 SDs of the mean (mean $=4.8, S D$ $=1.4)$. 




Figure 9. Disappearance of rabbit macrophage-derived TNF from plasma after intravenous injection in either normal or LPS pretreated rabbits. Femoral artery cannulation was performed to facilitate collection of blood samples and the rabbits were placed in restraining suits as described in Methods. After injection of TNF (either ${ }^{125}$ I-TNF or unlabeled TNF) blood samples were collected and analyzed for residual counts per minute using a gamma counter, or for residual TNF activity using the L929 cytolytic assay.

were comparable to those of control rabbits that did not receive LPS.

Because inhibitors of TNF cytolytic activity were not detected in serum samples collected either before or after injection of LPS, we felt that by incorporating the observed parameters into a mathematical model of the LPS-induced TNF release, we would obtain a reasonable approximation of the total amount of TNF released into the plasma compartment. Accordingly, we constructed a model consisting of the following:

$$
\begin{gathered}
\text { Compartment } 1 \stackrel{v}{\rightarrow} \text { Compartment } 2 \stackrel{k}{\rightarrow} \text { Compartment } 3 \\
\text { (TNF source) } \\
\text { (plasma, } \simeq 70 \mathrm{ml} \text { ) }
\end{gathered}
$$

The rate constant $k$ was set to $1 \mathrm{~min}^{-1}$ in accordance with the observed $t_{1 / 2}$ of the fast component (e.g., $k=\ln 2 / t_{1 / 2} ; t_{1 / 2}$ $=0.5-1 \mathrm{~min}$ ). The dependent variable, $v$ (velocity of TNF release from compartment 1 into compartment 2, expressed as $\mathrm{U} / \mathrm{min}$ ) was optimized at 1 -min intervals over $t=30 \mathrm{~min}$ to 200 min to yield TNF levels in compartment 2 that would agree with observed TNF levels in serum (Fig. 5). Following optimization of the incremental velocities over $t=30$ to 200 min, numerical integration was performed to determine the total amount of product released into compartment 2 . As shown in Fig. 10, the total amount of TNF transferred from compartment 1 to compartment 2 was calculated to be 2.2 $\times 10^{7} \mathrm{U}(220 \mu \mathrm{g}$, TNF). Recalculation of the model using the slow clearance rate $\left(t_{1 / 2}=11 \mathrm{~min}\right)$ suggested an absolute minimal estimate of TNF release of $8 \mu \mathrm{g}$. On the basis of $(a)$ extrapolation of the slow component of the disappearance curve (Fig. 9) to $t=0$, and (b) consideration of the $\sim 80 \%$ recovery of the intravenous injected TNF at $t=0.5 \mathrm{~min}$, we restructured the model using simultaneous half-lives of 0.69 and $11 \mathrm{~min}$ for 60 and $40 \%$, respectively, of the TNF in compartment 2 , and an estimated total release of $130 \mu \mathrm{g}$ TNF was obtained.

Infusion of human recombinant TNF followed by injection of parent LPS. The results shown in Fig. 8 demonstrated that maximal induction of TNF by LPS was followed by a period in

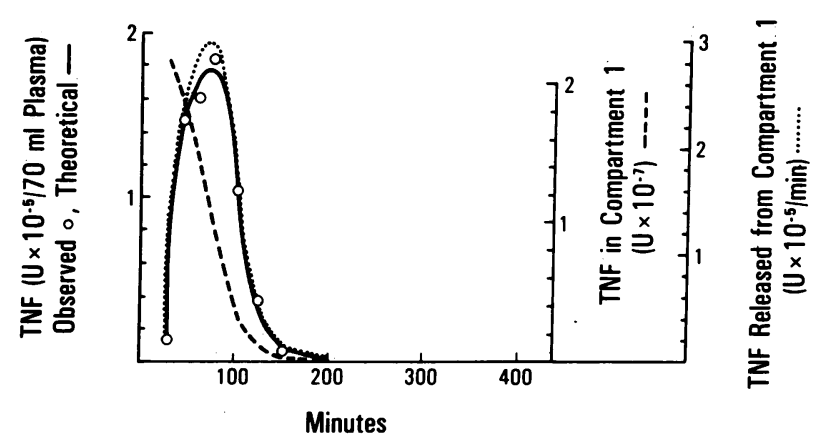

Figure 10. Kinetic model of TNF release and disappearance from plasma after intravenous injection of LPS in rabbits. In this computer simulation, TNF was released from compartment 1 (source) at the required velocity $(\mathrm{U} / \mathrm{min})$ to achieve plasma (compartment 2 ) levels consistent with experimentally observed values. The rate constant (k2) for clearance of TNF from compartment 2 was set to 1 $\min ^{-1}$ in accordance with the experimentally observed values for $t_{1 / 2}$ fast (Fig. 9). The TNF levels in compartment 2 are based on the observed plasma volume for 2-kg rabbits.

which further challenge with LPS induced no detectable TNF in the serum. To examine the possibility that TNF could mediate the hyporesponsive state the following experiment was performed. After placement of femoral artery and venous catheters, rabbits were put into restraining suits and HrTNF $(<0.1 \mathrm{ng}$ endotoxin $/ \mathrm{mg}$ ) was administered through the femoral vein cannula using an infusion pump that was programmed to deliver $200 \mu \mathrm{g}$ TNF over $30-150 \mathrm{~min}$ in proportion to the in vivo release velocities predicted by the model illustrated in Fig. 10. As shown in Fig. 11, serum TNF levels of $1 \times 10^{4} \mathrm{U} / \mathrm{ml}$ were observed over $60-100 \mathrm{~min}$ followed by return toward baseline levels by $250 \mathrm{~min}$. After injection of $10 \mu \mathrm{g}$ i.v. parent LPS (300 min) using the marginal ear vein, a second peak of cytolytic activity 4-7 $\times 10^{3} \mathrm{U} / \mathrm{ml}$ was observed over $345-375$ min. Thus hyporesponsiveness to LPS was not observed after infusion of HrTNF. During the infusion of TNF, core temperature increased $\sim 1.2^{\circ} \mathrm{C}$. However, MAP and WBC levels remained unchanged during the infusion (data not shown). When the HrTNF infusion was followed by Re595 LPS injection $24 \mathrm{~h}$ later, TNF release into the blood was detected with the same kinetics and extent observed in normal rabbits (data not shown).

In vivo neutralization of LPS-induced TNF. The results shown in Figs. 6 and 8 demonstrated an association between TNF release and hypotensive change, raising the possibility

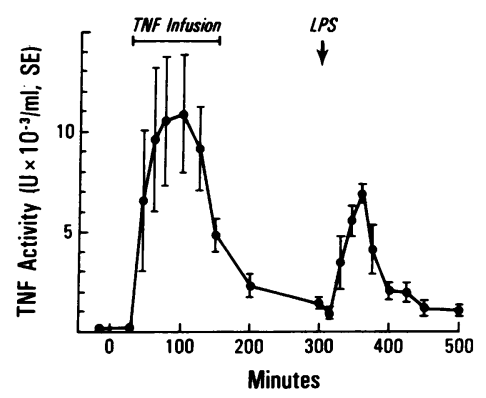

Figure 11. Effect of infusion of HrTNF on subsequent LPS induction of TNF in vivo. HrTNF $(200$ $\mu \mathrm{g}$, containing $<20 \mathrm{pg}$ endotoxin) was infused through the femoral vein catheter over 30-150 min in proportion to the in vivo release velocities predicted by the model shown in Fig. 10. Subsequently $(t=300$ min) $10 \mu \mathrm{g}$ Re595 LPS was injected using the marginal ear vein $(n=3)$. 




Figure 12. Pathophysiologic changes ${ }^{2}$ after injection of $250 \mu \mathrm{g}$ PA Re595 LPS in rabbits pretreated with antiTNF or NGG. Femoral artery cannulation was performed as described in Methods, and antibody or NGG was infused using the marginal ear vein $30 \mathrm{~min}$ before injection of LPS. The shaded area indicates MAP \pm SE for control rabbits as indicated in Fig. 6.

that TNF might participate in mediating of the decrease in MAP. Thus we performed the following experiments to determine if in vivo neutralization of TNF by infusion of anti-TNF antibody would alter the course of LPS-induced injury. The two experimental models described and shown in Figs. 5, 6, and 8 were used for these studies.

Single injection of $250 \mu g$ i.v. PA-LPS. After cannulation and placement in restraining suits, rabbits received an infusion of NGG or anti-TNF ( $8 \mathrm{ml}$ i.v. over $4 \mathrm{~min})$ at $t=-30 \mathrm{~min}$. In four of the rabbits, the primary infusion was followed by a second continuous slow infusion of $8 \mathrm{ml}$ beginning at $t=0$ and continuing until $t=60 \mathrm{~min}$. PA-LPS $(250 \mu \mathrm{g})$ was administered as a bolus at $t=0 \mathrm{~min}$. As shown in Fig. 12, peak TNF levels of $2.5-3 \times 10^{3} \mathrm{U} / \mathrm{ml}$ were observed over $45-100 \mathrm{~min}$ in rabbits that were pretreated with NGG. Prior infusion of antiTNF resulted in $>95 \%$ neutralization of the LPS-induced cytolytic activity. Furthermore, additional slow infusion of antibody did not result in more complete neutralization of TNF or provide greater protection from the hypotension changes (data not shown). Persistence of the anti-TNF antibody in plasma of control animals and the clearance of antibody from plasma of LPS-treated rabbits is shown in Table IV.

In the NGG-treated rabbits MAP fell $15-20 \%$ over 0-75 min and continued to decline over 100-500 min for a total decrease of $40 \%$. In contrast, MAP remained in the normal range in rabbits that were pretreated with anti-TNF. Using the distribution-free analysis of Koziol (29) the differences in MAP between the antibody-and NGG-pretreated rabbits were found to be significant $(P=0.014)$. Both groups of animals, NGG and anti-TNF pretreated, developed leukopenia followed by partial recovery of cell counts to the normal range.

Multiple injections, $10 \mu \mathrm{g}$ i.v. parent Re595 LPS. Because $10 \mu \mathrm{g}$ of parent LPS was the smallest dose that resulted in maximal induction of TNF, this dose was selected to examine more closely the protection afforded by infusion of anti-TNF antibody. After cannulation and placement of rabbits in restraining suits, infusions of anti-TNF, NGG or saline $(8 \mathrm{ml}$ injection over 4 min using the marginal ear vein) were made 45 min before injection of a $10-\mu \mathrm{g}$ bolus of parent LPS. As
Table IV. Anti-TNF Levels* Remaining in Serum after Injection of $8 \mathrm{ml}$ i.v. Anti-TNF Globulin Fraction in Rabbits that Received either Parent LPS or PA-LPS

\begin{tabular}{|c|c|c|c|c|c|c|}
\hline \multirow[b]{2}{*}{$\begin{array}{c}\text { Time of } \\
\text { anti-TNF injection }\end{array}$} & \multirow[b]{2}{*}{ Injection at $t=0^{\ddagger}$} & \multicolumn{5}{|c|}{ Minutes post injection of LPS } \\
\hline & & -15 & 30 & 100 & 300 & 500 \\
\hline $\min$ & & & & Titer & & \\
\hline-30 & Saline & $10^{8}$ & 6 & 6 & —"I & 4 \\
\hline 210 & Parent LPS & - & - & - & 10 & 9 \\
\hline-30 & PA-LPS & 5 & 6 & 1.5 & 1.5 & 1.5 \\
\hline-45 & Parent LPS & 6 & 一 & 2.5 & 2.5 & 2.5 \\
\hline
\end{tabular}

* Equal volumes of PEM-TNF (conditioned medium from parent LPS-treated rabbit PEM, $1 \times 10^{3} \mathrm{U} / \mathrm{ml}$ ) and serum samples (neat or diluted) from LPS-treated rabbits were incubated for $30 \mathrm{~min}$ at $37^{\circ} \mathrm{C}, 5 \% \mathrm{CO}_{2}$, and then tested for residual cytolytic activity in the L929 cell assay. The antibody titer is defined as the serum dilution giving 50\% neutralization of the TNF cytolytic activity.

${ }_{\ddagger} 10 \mu \mathrm{g}$ parent LPS, $250 \mu \mathrm{g}$ PA-LPS, or saline ( $1 \mathrm{ml}$ total volume) was administered using the marginal ear vein at $t=0$.

$\$$ On the basis of the titer of the administered anti-TNF (Fig. 4) and the plasma volume of the rabbits $(\sim 70 \mathrm{ml})$ an initial titer of nine was expected.

" Titer not determined.

shown in Fig. 13 serum TNF levels of $2-3 \times 10^{3} \mathrm{U} / \mathrm{ml}$ were observed over 60-100 min in the saline and NGG pretreated rabbits, and MAP were decreased $30-40 \%$ over 500 min. In contrast, serum TNF levels of anti-TNF pretreated rabbits were below the threshold of the assay, and MAP remained within the lower limits of the normal range $(P=0.021)$. As shown in Table IV serum anti-TNF antibody levels were significantly reduced $100 \mathrm{~min}$ postinjection of $10 \mu \mathrm{g}$ parent LPS. In contrast anti-TNF antibody persisted in the circulation when administered at $t=215 \mathrm{~min}$ (after the first dose of LPS at $t=0$ but before the second dose of LPS at $t=300 \mathrm{~min}$ ). WBC

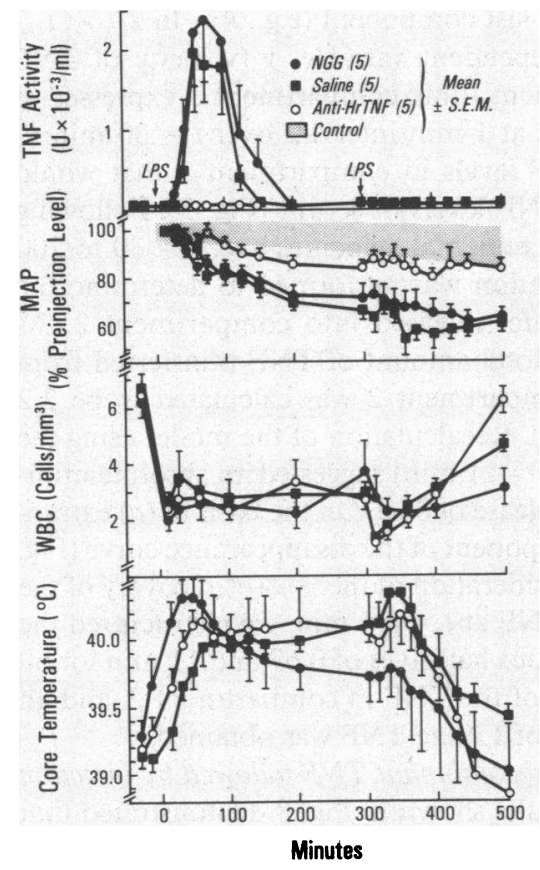

Figure 13. Pathophysiologic changes ${ }^{2}$ after injection of $10 \mu \mathrm{g}$ i.v. parent Re595 LPS in rabbits that were pretreated with anti-TNF, NGG or saline. Femoral artery cannulation was performed as described in Methods, and antibody, NGG, or saline was infused at $t=-45 \mathrm{~min}$ using the marginal ear vein followed by injection of LPS at $t=0$ $\min$ and $300 \mathrm{~min}$. The shaded area indicates $\mathrm{MAP} \pm \mathrm{SE}$ for control rabbits as indicated in Fig. 6. 
Table V. Pathophysiologic Changes after Multiple Injections of $10 \mu \mathrm{g}$ Parent Re595 LPS in Rabbits Pretreated with Anti-TNF, NGG, or Saline*

\begin{tabular}{lccc}
\hline & Anti-TNF & NGG & Saline \\
\hline Survival at 24 h & $5 / 5$ & $0 / 5$ & $0 / 5$ \\
Mean survival time & $24 \mathrm{~h}+75 \mathrm{~min}$ & $12 \mathrm{~h}$ & $12 \mathrm{~h}$ \\
500-min parameters & & & \\
$\quad$ MAP & $77 \pm 3$ & $59 \pm 5$ & $58 \pm 4$ \\
CT & $38.7 \pm 0.2$ & $39.0 \pm 0.6$ & $39.4 \pm 0.1$ \\
WBC & $6,200 \pm 460$ & $3,100 \pm 620$ & $4,660 \pm 200$ \\
24-h parameters & & & \\
MAP & $60 \pm 4.9$ & - & - \\
CT & $38.0 \pm 0.54$ & - & - \\
WBC & $9,200 \pm 1,500$ & - & - \\
\hline
\end{tabular}

* Rabbits were pretreated with anti-TNF, NGG, or saline ( $8 \mathrm{ml}$ i.v.) at $t=-45 \mathrm{~min}$. LPS (10 $\mu \mathrm{g}$ in $1 \mathrm{ml}$ i.v. saline) was injected at $t=0$, $300 \mathrm{~min}$, and $24 \mathrm{~h}$.

levels and core temperatures were not significantly different between the three groups. The second dose of LPS $(t=300$ min) did not induce detectable levels of TNF, and the hypotensive change was not significantly accelerated. At the conclusion of the 500 -min monitoring period the surgical wounds were sutured, and the rabbits were returned to cages for overnight observation. Animals recognized as being moribund (e.g., MAP $<55 \mathrm{mmHg}$ and $\mathrm{CT}<36^{\circ} \mathrm{C}$ ) were killed by injection of sodium pentobarbital, and autopsies were performed. At $t=24 \mathrm{~h}$, monitoring of MAP and CT was resumed, and a final injection of $10 \mu \mathrm{g}$ parent LPS was made. As shown in Table V, 5/5 of the anti-TNF treated rabbits survived $>24 \mathrm{~h}$, whereas none of the animals in the NGG- and saline-pretreated groups survived $24 \mathrm{~h}$. Examination of fixed-tissues at the light microscopic level revealed the following patterns of changes in NGG- and saline-pretreated rabbits: (a) focal hepatic necrosis with fibrin deposition in sinusoids, $(b)$ fibrin deposits in glomerular capillaries and focal tubular necrosis, (c) splenic necrosis with fibrin deposits and accumulation of neutrophils, $(d)$ pulmonary changes of varying degree including edema, atelectasis, and fibrin deposition. In contrast, pathologic changes in tissues from anti-TNF treated rabbits were considerably less severe and were limited to: $(a)$ minimal eosinophilic deposits in Kupffer cells of the liver, $(b)$ occasional protein casts in renal tubules, $(c)$ mild edema and proteinacious deposits in splenic sinusoids, and $(d)$ pulmonary edema and atelectasis. Assessment of fibrin deposition and tissue necrosis changes observed in liver and kidney for the three groups are summarized in Table VI.

\section{Discussion}

We have examined the role of TNF as a mediator of LPS-induced injury in a rabbit model of endotoxic shock. TNF is rapidly induced in vivo after intravenous injection of two different forms of LPS: either parent Re595 LPS or PA-LPS (LPS-HDL complexes). Using a kinetic model based on the observed $t_{1 / 2}$ for purified rabbit TNF and peak levels of LPSinduced cytolytic activity in vivo, we estimated that $\sim 130 \mu \mathrm{g}$ of TNF was released into the plasma compartment 30-200 min after injection of LPS. Infusion of anti-TNF antibodies resulted in neutralization of LPS-induced serum cytolytic activity, blunting of the hypotensive changes, prevention of fibrin deposition as well as focal hepatic necrosis and protection from lethality. Thus these studies provide support for the concept that TNF is an essential mediator of LPS induced injury and acts by initiating the primary changes that lead to the cascade of events culminating in lethal hypotensive shock and DIC.

Induction of TNF by Re595 LPS. We have shown previously that intravenously administered parent Re595 LPS is rapidly cleared from the circulation and taken up by macrophages in high concentrations that are easily detected by autoradiography (8). However, exposure of parent LPS to plasma or serum results in reduction of the aggregate size of the LPS followed by formation of LPS-HDL complexes $(5,33)$. In previous studies, we found that after intravenous injection, LPSHDL complexes persisted in plasma $\left(t_{1 / 2}>12 \mathrm{~h}\right)$, and intracellular concentrations of this form of LPS were too low to permit convincing demonstration of subcellular localization (8). In the present study the more efficient induction of TNF by parent LPS (maximal at $5 \mu \mathrm{g} / \mathrm{kg}$ ) versus PA-LPS (maximal at $125 \mu \mathrm{g} / \mathrm{kg}$ ) suggests that macrophages, which are the primary targets for the parent LPS, are also the primary source of TNF in vivo, although other cells, including lymphocytes may contribute to the response $(37,38)$. Similarly, we observed that parent LPS was approximately two logs more efficient than LPS-HDL in inducing TNF in rabbit PEM in vitro (Fig. 1). Thus two forms of LPS, parent and LPS-HDL, which might gain exposure to macrophages during gram negative sepsis, induce TNF in vivo although formation of LPS-HDL complexes may serve to limit stimulation of macrophages and the resulting release of TNF and other monokines.

Table VI. Histopathologic Changes in Rabbits that Received Multiple Injections of 10 mg Parent Re595 LPS

\begin{tabular}{llll}
\hline & \multicolumn{1}{c}{ Anti-TNF } & \multicolumn{1}{c}{ NGG } & \multicolumn{1}{c}{ Saline } \\
\hline Liver & & & $4 / 5$ (Moderate to severe) \\
$\quad$ Focal necrosis & $1 / 5$ (Minimal $\left.^{*}\right)$ & $5 / 5$ (Moderate to severe $\left.^{\ddagger}\right)$ & $3 / 5$ (Minimal) \\
Sinusoidal fibrin deposits & $0 / 5$ & $4 / 5$ (Minimal) & $3 / 5$ (Minimal to marked) \\
Kidney & $1 / 5$ (Minimal ${ }^{8}$ ) & $3 / 5$ (Minimal to marked") & $0 / 5$ \\
$\quad$ Glomerular fibrin deposits & $1 / 5$ (Focal) & $3 / 5$ (Focal to diffuse) & \\
Tubular necrosis & &
\end{tabular}

\footnotetext{
* Occasional foci (50-100 $\mu \mathrm{m}$ diam). ${ }^{\ddagger}$ Multiple sites (> $100 \mu \mathrm{m}$ diam lesion). ${ }^{8}$ Local, occasional capillary loop; and focal, occasional glomerulus. "Generalized, entire glomerulus; and focal, 5-30\% of glomeruli involved.
} 
Beutler et al. have suggested that cachectin/TNF represents $1-5 \%$ of the proteins generated by LPS-treated RAW 264.7 cells, a murine macrophage cell line (39). We have observed that when RAW cells and rabbit PEM are stimulated by $R e 595$ LPS under standard conditions $\left(0.1 \mu \mathrm{g} \mathrm{LPS} / \mathrm{ml}, 8 \times 10^{7}\right.$ cells per $150 \mathrm{~cm}^{2}$ flask containing $20 \mathrm{ml}$ serum-free RPMI 1640, 18 $h$ at $37^{\circ} \mathrm{C}, 5 \% \mathrm{CO}_{2}$ ) the RAW cell-conditioned medium generally contains fivefold greater cytolytic activity than the PEM conditioned medium (data not shown). Using the specific activity determined in the present studies for rabbit PEM TNF (1 $\times 10^{8} \mathrm{U} / \mathrm{mg}$ ) and the observed TNF titers of conditioned medium from LPS-treated PEM $\left(\sim 1.5 \times 10^{3} \mathrm{U} / \mathrm{ml}\right)$ we estimate a maximum TNF concentration of $15 \mathrm{ng} / \mathrm{ml}$. This represents $\sim 0.1 \%$ of the total protein released. Comparable TNF protein levels ( $\sim 10 \mathrm{ng}$ TNF per $\mathrm{ml}$, corresponding to $0.02 \%$ of the total protein released) were observed in conditioned medium from 4B-phorbol 12-myristate 13-acetate-treated HL-60 cells (32). While TNF may be a major secretory product of some transformed lines such as RAW 264.7 it is not appropriate to assume this conclusion holds for all other macrophage sources.

Production and clearance of TNF in vivo. In order to estimate the amount of TNF released into plasma over the 30-200-min period after injection of LPS, we employed a kinetic model based on: $(a)$ the observed peak TNF levels $(\sim 2.5$ $\times 10^{3} \mathrm{U} / \mathrm{ml}$, corresponding to $1.4 \mathrm{nM}$ ) observed after injection of LPS and $(b)$ the observed disappearance rates of purified rabbit TNF $\left(t_{1 / 2}\right.$ fast component $=0.5-1 \mathrm{~m}, t_{1 / 2}$ slow component $=11 \mathrm{~min}$ ). When the incremental velocity of TNF release into the plasma compartment was optimized to yield computed plasma TNF levels consistent with experimentally observed values, we obtained a calculated value of $1.3 \times 10^{7} \mathrm{U}$ (corresponding to $130 \mu \mathrm{g}$ ) TNF released over the 30-200-min period (based on the plasma volume of a $2-\mathrm{kg}$ rabbit). The observed biphasic disappearance (Fig. 9) suggests that two forms of TNF are cleared from plasma, perhaps depending on the degree of aggregation $(40,41)$. Another possibility is that the slow component represents TNF in equilibrium between plasma and receptors (e.g., on endothelium and leukocytes). However, because a significant proportion of the TNF released would be rapidly and irreversibly bound to receptors it is possible that this calculated value represents an underestimate of the total amount actually released.

The measurements of serum TNF represented here are consistent with reports from other laboratories although the animal models used differ. For example, Ruff and Gifford observed TNF levels of $7.5 \times 10^{3} \mathrm{U} / \mathrm{ml}$ in serum from BCG pretreated rabbits that were bled $90 \mathrm{~min}$ after an injection of $100 \mu \mathrm{g}$ i.v. LPS (42). Haranaka et al. purified TNF from serum collected 90 min after injection of $100 \mu \mathrm{g} \mathrm{E}$. coli 0111:B4 LPS in $P$. acnes primed rabbits (25). On the basis of the specific activity of the purified TNF, the TNF concentration in the starting material serum was $225 \mathrm{ng} / \mathrm{ml}$ (12.5 nM). Beutler et al. observed cachectin/TNF levels in the nanomolar range $2 \mathrm{~h}$ after injection of LPS in unprimed rabbits (43).

The half-life of TNF determined in our studies is in the range reported for a number of different cytokines including TNF (43-47). Our studies demonstrate good agreement between TNF clearance data obtained by radioisotope tracer measurements and by measurements of TNF cytolytic activity (Fig. 9). Of interest is the observation that the clearance rate of TNF is the same in LPS-pretreated and nontreated animals despite the fact that the LPS-pretreated animals received a dose of Re595 LPS that elicits a maximum TNF response. Our data suggest that prior exposure of TNF does not alter the clearance mechanisms although potentially important questions regarding the biologic response to a second exposure to TNF was not studied.

LPS-induced release of TNF into the serum occurs during a 30-200-min period of time following LPS injection. Additional exposure to LPS, whether in the form of LPS-HDL complexes that circulate with a long half-life $(36,48)$ or as multiple injections of parent LPS, does not result in additional TNF in the serum. The reasons for this lack of response are not known although we have attempted to explore several possibilities to account for this. Results shown in Table II exclude the presence of inhibitors of the TNF-bioassay in post-LPS serum. Additionally, when post-LPS serum was tested for the presence of inhibitors that would block LPS-induced TNF in explanted rabbit PEM, no such activity could be detected (Table III). One possibility not explored here is that the cell population responsible for TNF release into the serum becomes desensitized and is refractory to subsequent exposure to LPS. In this regard Fisch and Gifford (49) reported that following maximal LPS-induced TNF release rabbit alveolar macrophages did not release additional TNF upon challenge with more LPS. Beutler et al. reported similar results with RAW 264.7 cells (39).

We considered the possibility that the TNF released by macrophages could act in an autocrine manner to induce LPS-hyporesponsiveness, thus preventing further TNF release upon subsequent challenge by LPS. However, two lines of evidence from our studies suggest that TNF is not responsible for the hyporesponsive state. First, pretreatment of rabbits with HrTNF did not diminish the endogenous LPS-induced TNF response. As shown in Fig. 11, when HrTNF was infused in quantities $(200 \mu \mathrm{g})$ and rates to approximate as closely as possible in vivo release that would be induced following maximal stimulation by LPS, subsequent injection of $10 \mu \mathrm{g}$ parent LPS resulted in appearance of TNF activity in serum with normal kinetics and peak titers $\left(4-7 \times 10^{3} \mathrm{U} / \mathrm{ml}\right)$ that were increased approximately twofold over the normally observed levels. When LPS challenge was given $24 \mathrm{~h}$ after the HrTNF infusion, the resulting TNF levels $\left(2-3 \times 10^{3} \mathrm{U} / \mathrm{ml}\right)$ were comparable to those observed in normal rabbits that received LPS. A second, though indirect line of evidence suggesting that TNF itself does not mediate hyporesponsiveness to LPS is derived from the anti-TNF pretreatment studies. As shown in Fig. 13 and Table IV, anti-TNF globulin pretreatment resulted in neutralization of LPS-induced serum TNF activity, and in addition, the administered antibody was substantially depleted from the serum. A second injection of LPS failed to induce detectable serum TNF levels or lead to further reduction of the anti-TNF titers in serum. Thus, in these animals hyporesponsiveness was induced by LPS in the absence of detectable levels of serum TNF. Further studies to elucidate the mechanisms of the hyporesponsive state are under way in our laboratory.

Role of TNF in the mediation of LPS-induced injury. The work described here provides the basis for continued studies to unravel the mechanism(s) of TNF action and therefore the mechanism(s) of LPS induced injury. We have used rabbits that have not received any systemic anesthesia, are responsive to relatively low concentrations of a highly purified, well characterized LPS preparation and are protected by passive administration of a globulin fraction of anti-TNF serum. Impor- 
tantly, this antibody was prepared against recombinant human TNF so that antibodies to other monokines would not be present. ${ }^{3}$ Both the protective and control globulin fractions have been shown to be free of contamination by endotoxin, the presence of which could confound interpretation of experimental data.

The pathophysiologic changes observed after bolus injection of $10 \mu \mathrm{g}$ i.v. parent Re595 LPS include: (a) hypotensive responses characterized by decrease in MAP 45-100 min after injection of LPS followed by further decline in MAP over 100-500 min, (b) fibrin deposition (primarily in renal glomeruli) and focal hepatic necrosis with increased numbers of marginated PMN in capillaries and sinusoids of the tissues examined, and $(c)$ death within $12 \mathrm{~h}$ of injection of LPS. In previous studies we have provided evidence that these changes do not require complement activation (48, 50-52). Moreover, other mediators derived from multiple sources have been considered (1) but no single mediator has been identified as being a major element in the initiation of LPS-induced injury.

In the present study, pretreatment with anti-TNF antibody resulted in elimination of the TNF observed in the serum during the 30-200-min period post-LPS. Associated with this neutralization of TNF is reduction of LPS-induced hypotension, abrogation of focal hepatic necrosis and fibrin deposition in liver and kidneys and prevention of lethality. The release of TNF into the blood during the period 30-200 min post-LPS appears to be essential for the evolution of injury since pretreatment with anti-TNF globulin markedly blunts LPS-induced injury while administration of anti-TNF globulin at 215 min post-LPS does not reverse any of the pathophysiologic changes (data not shown). These data support the concept that TNF is a primary mediator of LPS-induced injury initiating changes that lead to a diverse spectrum of cellular injury. Infusion of HrTNF resulted in fever without alterations of MAP or WBC levels (Fig. 11), suggesting that circulating TNF alone, in the absence of additional factors, does not mediate all of the pathophysiologic changes that are induced by LPS. Thus the initial production of TNF is necessary, though not sufficient to lead to full development of injury, and may act by sensitizing the host to the action of other mediators induced by LPS or through potential autocrine effects of TNF itself (53-55).

Critical issues that remain unresolved are the identity of the cellular targets of TNF in vivo and the mechanism(s) by which TNF alters cell phenotype to lead to injury. A number of recent studies have provided evidence that interactions between TNF endothelial cells and neutrophils (56-67) could produce changes that are relevant to many LPS-induced pathophysiologic changes. Binding of TNF to neutrophils results in enhanced adherence of the PMN to endothelial cells (58-60), inhibition of migration (56), stimulation of respiratory burst and degranulation $(61,62)$. In addition, Shalaby et al. observed disruption of endothelial cell monolayers in vitro by TNF treated PMN (56). Interaction of TNF with endothelial cells has been shown to result in: $(a)$ reorganization (elongation, overlapping of cells, rearrangement of actin filaments and loss of stainable fibronectin matrix) (63) (b) expression of tissue factor-like procoagulant activity $(64,65)(c)$ diminished

3. The anti-TNF serum used here does not neutralize the cytolytic activity of human recombinant TNF- $\beta$ (lymphotoxin). J. M. Dayer, M.D., Geneva, Switzerland, personal communication. expression of thrombomodulin activity (64), $(d)$ increased expression of plasminogen activator inhibitor (PAI-1) $(66,67)$ and $(e)$ adherence of PMN to endothelial cells $(58,59)$. In addition, van Hinsbergh et al. observed increased plasma PAI in rats $2 \mathrm{~h}$ after a bolus injection of $2.5 \times 10^{5} \mathrm{UTNF} / \mathrm{kg}$ (equivalent to $\sim 10 \mu \mathrm{g} \mathrm{TNF} / \mathrm{kg}$ ) (67). Finally, Remick et al. (18) reported endothelial cytoplasmic blebbing and gap formation between endothelial cells in mice $2 \mathrm{~h}$ after injection of TNF (50 $\mu \mathrm{g} \mathrm{HrTNF/kg).} \mathrm{Recently,} \mathrm{in} \mathrm{studies} \mathrm{of} \mathrm{the} \mathrm{mecha-}$ nisms of TNF action, Kettlehut et al. provided evidence that cyclooxygenase inhibitors provided protection from rapid killing, eventual lethality and other pathophysiological changes that were induced by injection of human recombinant TNF (4 $\mathrm{mg} / \mathrm{kg}$ i.v.) in rats (68). Altogether these findings suggest a number of mechanisms for LPS-induced pathophysiologic changes; nevertheless, it is likely that further elements of the injury pathways remain to be considered. For example, could hypotensive changes be mediated in part by endothelium-derived relaxing factors induced in endothelial cells, either directly by LPS or indirectly by TNF, IL-1 or other cytokines (69).

Whether TNF participates as a primary mediator of injury during gram-negative septicemia in man is at present unknown. Results from recent clinical studies suggest that detectable TNF levels in septic patients are considerably lower than the nanomolar levels induced in experimental animals by infusion of purified LPS or bacteria. For example, Wage et al. (70) used a cytolytic assay (WEHI 164 clone 13 cells) to measure TNF levels in sera from 79 patients with menningoccal disease and found that the majority, (61/79) were below the detection limit of the assay $(<2 \mathrm{pg} / \mathrm{ml})$. TNF levels in the remaining samples ranged in general from 2 to $300 \mathrm{pg} / \mathrm{ml}$, and all of the patients $(5 / 79)$ with TNF levels $>0.1 \mathrm{ng} / \mathrm{ml}$ died (70). In an earlier study, $3 / 23$ septic patients were found to have TNF levels of $3-20 \mathrm{pg} / \mathrm{ml}$ (71). Tracy et al. employed a skeletal muscle depolarization assay to detect picomolar levels of TNF in plasma samples of critically ill patients $(72,73)$. Using an ELISA with a sensitivity of $39 \mathrm{pg} \mathrm{TNF} / \mathrm{ml}$, Scuderi et al. observed that TNF levels were frequently elevated in patients with kala-azar or malaria (67 and $70 \%$, respectively; geometric mean $119 \mathrm{pg} / \mathrm{ml}$ ) (74). However in view of the rapid and apparently evanescent release of TNF in animals it may be difficult to detect elevated levels of TNF in serum in patients where initial exposure to an inducer such as LPS occurred prior to clinical observation.

Nevertheless, the studies described here document a central role for TNF in mediating endotoxin-induced injury, support and extend the observations of others $(15-18,68)$ and provide a reproducible, easily controlled experimental animal model where the possible mechanisms of TNF action suggested from in vitro studies can be evaluated. Thus our recently acquired knowledge of the identity of a central mediator of LPS induced injury, TNF, promises to accelerate the understanding of the mechanisms of LPS-induced injury and the development of new therapeutic approaches for management of patients with gram negative sepsis.

\section{Acknowledgments}

We gratefully acknowledge the following people for their contributions: Charles Cochrane for helpful discussions and evaluation of the histologic sections; Larry Sklar and Bill Swann for suggestions and 
assistance in construction of the kinetic models of TNF release; James Koziol and Oliver Ulyett for assistance in performing statistical analysis of the data; Lois Kline for performing the IL-1 assays; Peter Tobias and Katrin Soldau for performing the immunoassays for anti-LPS antibody and Velda Comstock for preparation of the manuscript. The human recombinant TNF used in these studies was provided by Cetus Corporation, Emeryville, CA. We also thank David Mark, Leo Lin and Abla Creasey of Cetus Corporation for their support.

Publication \# 4960 IMM from the Department of Immunology. Supported by US Public Health Service grants AI-15136 and GM 28485.

\section{References}

1. Morrison, D. C., and R. J. Ulevitch. 1978. The effects of bacterial endotoxins on host mediation systems. Am. J. Pathol. 93:527-617.

2. Westphal, O. 1975. Bacterial endotoxins. Int. Arch. Allergy Appl. Immunol. 49:1-43.

3. Crutchley, M. J., D. G. Marsh, and J. Cameron. 1967. Immunology: free endotoxin. Nature (Lond.). 214:1052.

4. Gilbert, R. P. 1960. Mechanisms of the hemodynamic effects of endotoxin. Physiol. Rev. 40:245-279.

5. Ulevitch, R. J., A. R. Johnston, and D. B. Weinstein. 1979. New function for high density lipoproteins: their participation in intravascular reactions of bacterial lipopolysaccharides. J. Clin. Invest. 64:1516-1524.

6. Tobias, P. S., and R. J. Ulevitch. 1983. Control of lipopolysaccharide-high density lipoprotein binding by acute phase protein(s). $J$. Immunol. 131:1913-1916.

7. Tobias, P. S., K. Soldau, and R. J. Ulevitch. 1986. Isolation of a lipopolysaccharide-binding acute phase reactant from rabbit serum. $J$. Exp. Med. 164:777-793.

8. Mathison, J. C., and R. J. Ulevitch. 1979. The clearance, tissue distribution, and cellular localization of intravenously injected lipopolysaccharide in rabbits. J. Immunol. 123:2133-2143.

9. Glode, L. M., S. E. Mergenhagen, and D. L. Rosenstreich. 1976. Significant contribution of spleen cells in mediating the lethal effects of endotoxin in vivo. Infect. Immun. 14:626-630.

10. Freudenberg, M. A., D. Keppler, and C. Galanos. 1986. Requirement for lipopolysaccharide-sensitive macrophages in galactosamine-induced sensitization to endotoxin. Infect. Immun. 51:891895.

11. Nathan, C. F. 1987. Secretory products of macrophages. $J$. Clin. Invest. 79:319-326.

12. Beutler, B., and A. Cerami. 1986. Cachectin and tumour necrosis factor as two sides of the same biological coin. Nature (Lond.). 320:584-588.

13. Beutler, B., and A. Cerami. 1987. Cachectin: more than a tumor necrosis factor. N. Engl. J. Med. 316:379-385.

14. Beutler, B., D. Greenwald, J. D. Hulmes, M. Chang, Y.-C. E. Pan, J. Mathison, R. Ulevitch, and A. Cerami. 1985. Identity of tumour necrosis factor and the macrophage-secreted factor cachectin. Nature (Lond.). 316:552-554.

15. Beutler, B., I. W. Milsark, and A. C. Cerami. 1985. Passive immunization against cachectin/tumor necrosis factor protects mice from lethal effect of endotoxin. Science (Wash. DC). 29:869-871.

16. Tracey, K. J., B. Beutler, S. F. Lowry, J. Merryweather, S. Wolpe, I. W. Milsark, R. J. Hariri, T. J. Fahey III, A. Zentella, J. D. Albert, G. T. Shires, and A. Cerami. 1986. Shock and tissue injury induced by recombinant human cachectin. Science (Wash. DC). 234:470-474.

17. Tracey, K. J., S. F. Lowry, T. J. Fahey III, J. D. Albert, Y. Fong, D. Hesse, B. Beutler, K. R. Manogur, S. Calvano, H. Wei, A. Cerami, and G. T. Shires. 1987. Cachectin/tumor necrosis factor induces lethal shock and stress hormone responses in the dog. Surg. Gynecol. Obs. 164:415-422.

18. Remick, D. G., R. G. Kunkel, J. W. Larrick, and S. L. Kunkel.
1987. Acute in vivo effects of human recombinant tumor necrosis factor. Lab. Invest. 56:583-590.

19. Galanos, C., O. Luderitz, and O. Westphal. 1969. A new method for the extraction of R lipopolysaccharides. Eur. J. Biochem. 9:245-249.

20. Cynkin, M. A., and G. Ashwell. 1960. Biochemistry: estimation of 3-deoxy sugars by means of the malonaldehyde-thiobarbituric acid reaction. Nature (Lond.). 186:155-156.

21. Ruff, M. R., and G. E. Gifford. 1981. Tumor necrosis factor. Lymphokine Res. 2:235-272.

22. Shipman, C., Jr. 1973. Trypsin. A. Mammalian tissues. In Tissue Culture. Methods and Applications. P. F. Kruse, Jr., and M. K. Patterson, Jr., editors. Academic Press, New York. 5-7.

23. Laemmli, U. K. 1970. Cleavage of structural proteins during the assembly of the head of bacteriophage T4. Nature (Lond.). 227:680-685.

24. Wray, W., T. Boulikas, V. P. Wray, and R. Hancock. 1981. Silver staining of proteins in polyacrylamide gels. Anal. Biochem. 118:197-203.

25. Haranaka, K., N. Satomi, A. Sakurai, and H. Nariuchi. 1985. Purification and partial amino acid sequence of rabbit tumor necrosis factor. Int. J. Cancer. 36:395-400.

26. Ito, H., S. Yamamoto, S. Kuroda, H. Sakamoto, J. Kajihara, T. Kiyota, H. Hayashi, M. Kato, and M. Seko. 1986. Molecular cloning and expression in Escherichia coli of the cDNA coding for rabbit tumor necrosis factor. $D N A(N Y)$. 5:149-156.

27. Fraker, P. J., and J. C. Speck, Jr. 1978. Protein and cell membrane iodinations with a sparingly soluble chloroamide, 1,3,4,6-tetrachloro-3a,6a-diphenylglycoluril. Biochem. Biophys. Res. Commun. 80:849-857.

28. Aster, R. H., and J. H. Jandl. 1964. Platelet sequestration in man. I. Methods. J. Clin. Invest. 43:843-854.

29. Koziol, J. A. 1984. VARCOV: a computer program for the distribution-free analysis of growth and response curves. Comput. Programs. Biomed. 19:69-74.

30. Scala, G., and J. J. Oppenheim. 1983. Antigen presentation by human monocytes: evidence for stimulant processing and requirement for interleukin 1. J. Immunol. 131:1160-1166.

31. Onozaki, K., K. Matsushima, B. B. Aggarwal, and J. J. Oppenheim. 1985. Human interleukin 1 is a cytocidal factor for several tumor cell lines. J. Immunol. 135:3962-3968.

32. Aggarwal, B. B., W. J. Kohr, P. E. Hass, B. Moffat, S. A. Spencer, W. J. Henzel, T. S. Bringman, G. E. Nedwin, D. V. Goeddel, and R. N. Harkins. 1985. Human tumor necrosis factor. Production, purification, and characterization. J. Biol. Chem. 260:2345-2354.

33. Ulevitch, R. J., and A. R. Johnston. 1978. The modification of biophysical and endotoxic properties of bacterial lipopolysaccharides by serum. J. Clin. Invest. 62:1313-1324.

34. Munford, R. S., J. M. Andersen, and J. M. Dietschy. 1981. Sites of tissue binding and uptake in vivo of bacterial lipopolysaccharidehigh density lipoprotein complexes. J. Clin. Invest. 68:1503-1513.

35. Freudenberg, M. A., T. C. Bog-Hansen, U. Back, and C. Galanos. 1980. Interaction of lipopolysaccharides with plasma high-density lipoprotein in rats. Infect. Immun. 28:373-380.

36. Munford, R. S., C. L. Hall, H. J. Lipton, and J. M. Dietschy. 1982. Biological activity, lipoprotein-binding behavior, and in vivo disposition of extracted and native forms of Salmonella typhimurium lipopolysaccharides. J. Clin. Invest. 70:877-888.

37. Rubin, B. Y., S. L. Anderson, S. A. Sullivan, B. D. Williamson, E. A. Carswell, and L. J. Old. 1986. Nonhematopoietic cells selected for resistance to tumor necrosis factor produce tumor necrosis factor. J. Exp. Med. 164:1350-1355.

38. Kobayashi, Y., M. Asada, and T. Osawa. 1987. Production of lymphotoxin and tumor necrosis factor by a T-cell hybridoma. Immunology. 60:213-217.

39. Beutler, B., J. Mahoney, N. LeTrang, P. Pekala, and A. Cerami. 1985. Purification of cachectin, a lipoprotein lipase-suppressing hor- 
mone secreted by endotoxin-induced RAW 264.7 cells. J. Exp. Med. 161:984-995.

40. Wingfield, P., R. H. Pain, and S. Craig. 1987. Tumor necrosis factor is a compact trimer. FEBS (Fed. Eur. Biochem. Soc.) Lett. 211:179-184.

41. Smith, R. A., and C. Baglioni. 1987. The active form of tumor necrosis factor is a trimer. J. Biol. Chem. 262:6951-6954.

42. Ruff, M. R., and G. E. Gifford. 1980. Purification and physicochemical characterization of rabbit tumor necrosis factor. J. Immunol. 125:1671-1677.

43. Beutler, B. A., I. W. Milsark, and A. Cerami. 1985. Cachectin/ tumor necrosis factor: production, distribution, and metabolic fate in vivo. J. Immunol. 135:3972-3977.

44. Donohue, J. H., and S. A. Rosenberg. 1983. The fate of interleukin-2 after in vivo administration. J. Immunol. 130:2203-2208.

45. Gutterman, J. U., M. G. Rosenblum, A. Rios, H. A. Fritsche, and J. R. Quesada. 1984. Pharmacokinetic study of partially pure gamma-interferon in cancer patients. Cancer Res. 44:4164-4171.

46. Flick, D. A., and G. E. Gifford. 1986. Pharmacokinetics of murine tumor necrosis factor. J. Immunopharmacol. 8:89-97.

47. Asher, A., J. J. Mule, C. M. Reichert, E. Shiloni, and S. A. Rosenberg. 1987. Studies on the anti-tumor efficacy of systemically administered recombinant tumor necrosis factor against several murine tumors in vivo. J. Immunol. 138:963-974.

48. Mathison, J. C., and R. J. Ulevitch. 1981. In vivo interaction of bacterial lipopolysaccharide (LPS) with rabbit platelets: modulation by C3 and high density lipoproteins. J. Immunol. 126:1575-1580.

49. Fisch, H., and G. E. Gifford. 1983. In vitro production of rabbit macrophage tumor cell cytotoxin. Int. J. Cancer. 32:105-112.

50. Ulevitch, R. J., C. G. Cochrane, P. M. Henson, D. C. Morrison, and W. F. Doe. 1975. Mediation systems in bacterial lipopolysaccharide-induced hypotension and disseminated intravascular coagulation. I. The role of complement. J. Exp. Med. 142:1570-1590.

51. Ulevitch, R. J., and C. G. Cochrane. 1978. Role of complement in lethal bacterial lipopolysaccharide-induced hypotensive and coagulative changes. Infect. Immun. 19:204-211.

52. Ulevitch, R. J., C. G. Cochrane, K. Bangs, C. M. Herman, J. R. Fletcher, and C. L. Rice. 1978. The effect of complement depletion on bacterial lipopolysaccharide (LPS)-induced hemodynamic and hematologic changes in the Rhesus monkey. Am. J. Pathol. 92:227-240.

53. Dinarello, C. A., J. G. Cannon, S. M. Wolff, H. A. Bernheim, B. Beutler, A. Cerami, I. S. Figari, M. A. Palladino, Jr., and J. V. O'Connor. 1986. Tumor necrosis factor (cachectin) is an endogenous pyrogen and induces production of interleukin 1. J. Exp. Med. 163:14331450.

54. Philip, R., and L. B. Epstein. 1986. Tumour necrosis factor as immunomodulator and mediator of monocyte cytotoxicity induced by itself, gamma-interferon and interleukin-1. Nature (Lond.). 323:8689.

55. Bachwich, P. R., S. W. Chensue, J. W. Larrick, and S. L. Kunkel. 1986. Tumor necrosis factor stimulates interleukin-1 and prostaglandin E2 production in resting macrophages. Biochem. Biophys. Res. Commun. 136:94-101.

56. Shalaby, M. R., M. A. Palladino, Jr., S. E. Hirabayashi, T. E. Eessalu, G. D. Lewis, H. M. Shepard, and B. B. Aggarwal. 1987. Receptor binding and activation of polymorphonuclear neutrophils by tumor necrosis factor-alpha. J. Leukocyte Biol. 41:196-204.

57. Nawroth, P. P., I. Bank, D. Handley, J. Cassimeris, L. Chess, and D. Stern. 1986. Tumor necrosis factor/cachectin interacts with endothelial cell receptors to induce release of interleukin 1. J. Exp. Med. 163:1363-1375.

58. Pohlman, T. H., K. A. Stannes, P. G. Beatty, H. D. Ochs, and J. M. Harlan. 1986. An endothelial cell surface factor(s) induced in vitro by lipopolysaccharide, interleukin 1 , and tumor necrosis factoralpha increases neutrophil adherence by a CDw18-dependent mechanism. J. Immunol. 136:4548-4553.

59. Gamble, J. R., J. M. Harlan, S. J. Klebanoff, and M. A. Vadas. 1985. Stimulation of the adherence of neutrophils to umbilical vein endothelium by human recombinant tumor necrosis factor. Proc. Natl. Acad. Sci. USA. 82:8667-8671.

60. Broudy, V. C., J. M. Harlan, and J. W. Adamson. 1987. Disparate effects of tumor necrosis factor-alpha/cachectin and tumor necrosis factor-beta/lymphotoxin on hematopoietic growth factor production and neutrophil adhesion molecule expression by cultured human endothelial cells. J. Immunol. 138:4298-4302.

61. Klebanoff, S. J., M. A. Vadas, J. M. Harlan, L. H. Sparks, J. R. Gamble, J. M. Agosti, and A. M. Waltersdorph. 1986. Stimulation of neutrophils by tumor necrosis factor. J. Immunol. 136:4220-4225.

62. Tsujimoto, M., S. Yokota, J. Vilcek, and G. Weissmann. 1986. Tumor necrosis factor provokes superoxide anion generation from neutrophils. Biochem. Biophys. Res. Commun. 137:1094-1 100.

63. Stolpen, A. H., E. C. Guinan, W. Fiers, and J. S. Pober. 1986. Recombinant tumor necrosis factor and immune interferon act singly and in combination to reorganize human vascular endothelial cell monolayers. Am. J. Pathol. 123:16-24.

64. Nawroth, P. P., and D. M. Stern. 1986. Modulation of endothelial cell hemostatic properties by tumor necrosis factor. J. Exp. Med. 163:740-745.

65. Bevilaqua, M. P., J. S. Pober, G. R. Majeau, W. Fiers, R. S. Cotran, and M. A. Gimbrone, Jr. 1986. Recombinant tumor necrosis factor induces procoagulant activity in cultured human vascular endothelium: characterization and comparison with the actions of interleukin 1. Proc. Natl. Acad. Sci. USA. 83:4533-4537.

66. Schleef, R. R., M. P. Bevilacqua, M. Sawdey, M. A. Gimbrone, and D. J. Loskutoff. 1987. Interleukin 1 (IL-1) and tumor necrosis factor (TNF) activation of vascular endothelium: effects on plasminogen activator inhibitor (PAI-1) and tissue-type plasminogen activator (tPA). J. Int. Soc. Thromb. Haemostasis. 58:17(65a). (Abstr.)

67. van Hinsbergh, V. W. M., T. Kooistra, W. Fiers, and J. J. Emeis. 1987. Tumor necrosis factor increases the production of plasminogen activator inhibitor in human endothelial cells in vitro and in rats in vivo. Thromb. Haemostasis. 58:15(59a). (Abstr.)

68. Kettelhut, I. C., W. Fiers, and A. L. Goldberg. 1987. The toxic effects of tumor necrosis factor in vivo and their prevention by cyclooxygenase inhibitors. Proc. Natl. Acad. Sci. USA. 84:4273-4277.

69. Palmer, R. M. J., A. G. Ferrige, and S. Moncada. 1987. Nitric oxide release accounts for the biological activity of endothelium-derived relaxing factor. Nature (Lond.). 327:524-526.

70. Waage, A., T. Espevik, and A. Halstensen. 1987. Association between tumour necrosis factor in serum and fatal outcome in patients with meningococcal disease. Lancet. i:355-357.

71. Waage, A., T. Espevik, and J. Lamvik. 1986. Detection of tumour necrosis factor-like cytotoxicity in serum from patients with septicaemia but not from untreated cancer patients. Scand. J. Immunol. 24:739-743.

72. Tracey, K. J., S. F. Lowry, B. Beutler, A. Cerami, J. D. Albert, and G. T. Shires. 1986. Chachectin/tumor necrosis factor mediates changes of skeletal muscle plasma membrane. J. Exp. Med. 164:1368-1373.

73. Tracey, K. J., S. F. Lowry, B. Beutler, A. Cerami, J. D. Albert, and G. T. Shires. 1986. Cachectin/tumor necrosis factor participates in reduction of skeletal muscle membrane potential: evidence for bioactivity in plasma during critical illness. Surg. Forum. 37:13-15.

74. Scuderi, P., K. S. Lam, K. J. Ryan, E. Petersen, S. E. Salmon, K. E. Sterling, P. R. Finley, C. G. Ray, and D. J. Slymen. 1986. Raised serum levels of tumour necrosis factor in parasitic infections. Lancet. ii: $1364-1365$. 